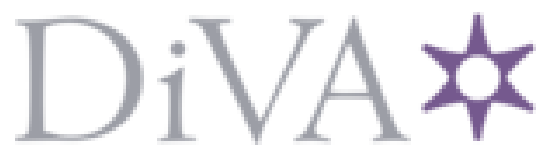

http://www.diva-portal.org

This is the published version of a chapter published in Industrial Applications of Nanomaterials.

Citation for the original published chapter:

Ye, X., Lendel, C., Langton, M., Olsson, R T., Hedenqvist, M S. (2019)

Protein Nanofibrils: Preparation, Properties, and Possible Applications in Industrial Nanomaterials

In: Thomas, S., Grohens, Y., Pottathara, Y. B. (ed.), Industrial Applications of Nanomaterials (pp. 29-63). Elsevier

https://doi.org/10.1016/B978-0-12-815749-7.00002-5

N.B. When citing this work, cite the original published chapter.

Permanent link to this version:

http://urn.kb.se/resolve?urn=urn:nbn:se:kth:diva-300413 


\title{
Protein nanofibrils:
}

\section{Preparation, properties, and possible applications in industrial nanomaterials}

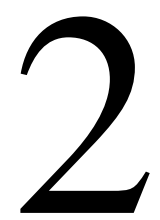

\author{
Xinchen Ye*, Christofer Lendel ${ }^{\dagger}$, Maud Langton ${ }^{\ddagger}$, Richard T. Olsson*, \\ Mikael S. Hedenqvist*
}

Department of Fiber and Polymer Technology, School of Engineering Sciences in Chemistry, Biotechnology and Health, KTH Royal Institute of Technology, Stockholm, Sweden* Department of Chemistry, School of Engineering Sciences in Chemistry, Biotechnology and Health, KTH Royal Institute of Technology, Stockholm, Sweden ${ }^{\dagger}$ Department of Molecular Sciences, SLU Swedish Agricultural University, Uppsala, Sweden

\section{Introduction to protein nanofibrils}

Protein nanofibrils (PNFs) are a new class of nanofibrils with an emerging application in composites. Compared with other fibrous nanoparticles (NPs), such as carbon nanotubes [1] and cellulose nanofibrils (Fig. 1) [2], PNFs have a similar appearance when imaged by, for example, atomic force microscopy (AFM) with diameters ranging from 5 to $10 \mathrm{~nm}$ and length up to several micrometers. They have a high content of $\beta$-sheet secondary structure that pack in so-called "cross- $\beta$ structure" with the $\beta$-strands perpendicular to the fibril axis and held together by a strong network of hydrogen bonds (see below) [3]. Their nanomechanical properties are quite remarkable [4] and they are also more resistant to enzymatic degradation than most other protein materials [5]. PNFs have already been shown to be excellent scaffolds for various functional materials and nanocomposites [6].

PNFs were first discovered in protein deposits found in certain pathological conditions known as systemic or localized amyloidosis (Table 1). More than 30 different proteins are known to form such disease-related fibrils, normally referred to as amyloid fibrils [7]. Most of the diseases are rare but some of them are indeed major challenges for the future health care, for example, Alzheimer's disease, Parkinson's disease, and type 2 diabetes. Another well-known group of amyloid-related disorders is the prion diseases (including, e.g., Creutzfled-Jakob in human and various disorders in animals, e.g., mad cow disease) in which the amyloid fibrils represent the infectious agent. Although the exact pathological mechanisms are not known for 


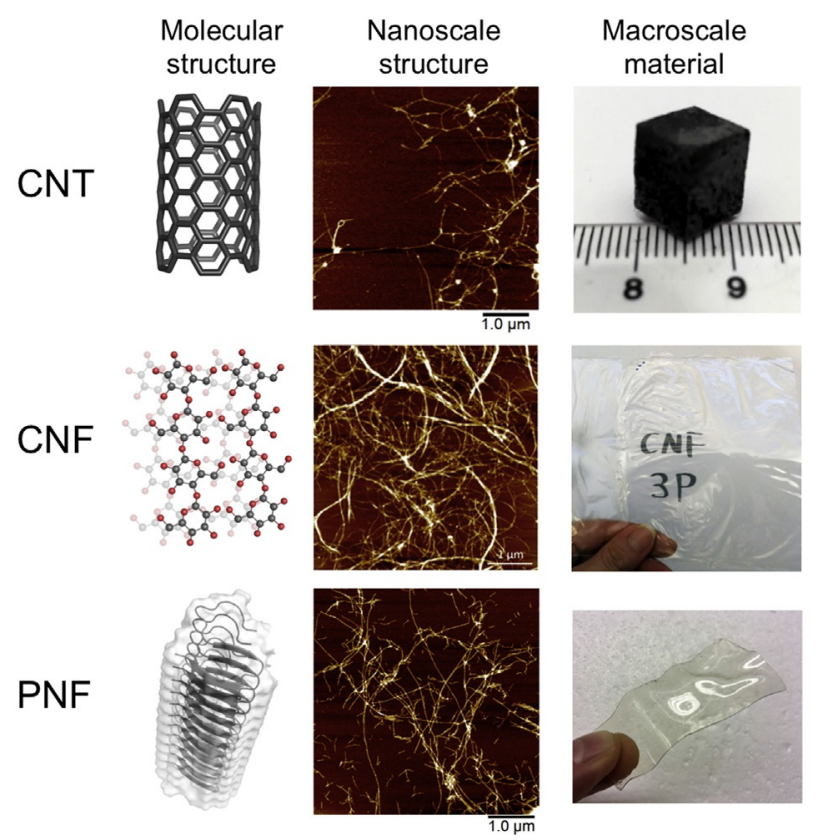

FIG. 1

Comparison of three types of fibrous nanoparticles used in nanocomposites. From left to right, the figure illustrates the molecular structures, the nanostructures imaged by AFM, and examples of macroscopical composite materials. CNT, carbon nanotubes; CNF, cellulose nanofibrils; PNFs, protein nanofibrils.

Table 1 Selected PNFs associated with human diseases [7]

\begin{tabular}{l|l} 
Protein & Disease \\
Immunoglobulin light chains & Amyloid light chain (AL) amyloidosis \\
Serum amyloid A1 protein & Amyloid A (AA) amyloidosis \\
$\beta 2$-Macroglobulin & Hemodialysis-related amyloidosis \\
Insulin & Injection-localized amyloidosis \\
Transthyretin & Senile systemic amyloidosis \\
Lysozyme & Lysozyme amyloidosis \\
Amylin (IAPP) & Type II diabetes \\
Amyloid- $\beta$ & Alzheimer's disease \\
Tau & Alzheimer's disease \\
$\alpha$-Synuclein & Parkinson's disease \\
Prion protein & Spongiform encephalopathies \\
Huntingtin & Huntington's disease \\
Superoxide dismutase I & Amyotrophic lateral sclerosis \\
\hline
\end{tabular}


many of these diseases, it is likely that the nanomechanical properties of the nanofibrils play a major role in their development. With this background in mind, it is not strange that massive research has been invested in trying to understand the properties and formation processes of PNFs.

More recently, protein fibrils with structures very similar to those found in the disease-associated deposits were found to have important roles in biologic functions (Table 2). The ability of forming PNFs has become a common property of a continuously expanding group of proteins ranging from bacteria and yeast to animals and even humans [6,17]. Typical functions of PNF structures include mechanical strength and adhesion but also more sophisticated functionalities such as epigenetic information transfer and catalytic scaffolds. These findings show that the PNF structure per se is not pathogenic, which opens the door to explore similar structures in designed materials. This has indeed inspired scientists to create PNF-based materials for different applications and the development was further promoted by the finding that proteins without any link to disease or biological function were also able to form fibrillar aggregates similar to those associated with diseases under appropriate conditions in vitro (Table 3) [38,39]. Taken together, it is now clear that the ability of forming amyloid-like structures is a common property of many proteins (potentially all), not only of a few proteins related to disease. So far, no toxic effects have been observed for the fibrils without connections to disease or biologic functions $[5,40]$, which opens for large-scale production of PNFs from industrial or agricultural waste streams.

Table 2 Selected PNFs associated with biological function, so-called functional amyloid

\begin{tabular}{|c|c|c|c|}
\hline Protein & Organism & Function & Reference \\
\hline CsgA (Curli) & Bacteria (E. coli) & Biofilm reinforcement & [8] \\
\hline FapC & $\begin{array}{l}\text { Bacteria } \\
\text { (Pseudomonas) }\end{array}$ & Biofilm reinforcement & [9] \\
\hline Sup35 & $\begin{array}{l}\text { Yeast } \\
\text { (Saccharomyces } \\
\text { cerevisiae) }\end{array}$ & $\begin{array}{l}\text { Epigenetics, protein } \\
\text { synthesis }\end{array}$ & [10] \\
\hline Ure2 & $\begin{array}{l}\text { Yeast } \\
\text { (Saccharomyces } \\
\text { cerevisiae) }\end{array}$ & $\begin{array}{l}\text { Epigenetics, nitrogen } \\
\text { catabolism }\end{array}$ & [11] \\
\hline HET-S & $\begin{array}{l}\text { Fungus (Podospora } \\
\text { anserina) }\end{array}$ & $\begin{array}{l}\text { Epigenetics (heterokaryon } \\
\text { incompatibility) }\end{array}$ & [12] \\
\hline Cp52k & Barnacle & $\begin{array}{l}\text { Strength, adhesion in } \\
\text { barnacle cement }\end{array}$ & {$[13,14]$} \\
\hline $\begin{array}{l}\text { Chorion } \\
\text { proteins }\end{array}$ & Insects & Protection of eggs & [15] \\
\hline Pmel17 & Human & $\begin{array}{l}\text { Catalytic scaffold for } \\
\text { melanin synthesis }\end{array}$ & [16] \\
\hline
\end{tabular}


Table 3 PNFs without known connection to disease or biologic function

\begin{tabular}{l|l|l} 
Protein & Source & Reference \\
$\beta$-Lactoglobulin & Whey (milk) & {$[18]$} \\
$\alpha$-Lactalbumin & Whey (milk) & {$[19]$} \\
Hemoglobin & Cow & {$[20]$} \\
Serum albumin & Cow & {$[21]$} \\
Parvalbumin & Fish & {$[22]$} \\
Crystalline & Fish eyes & {$[23]$} \\
Ovalbumin & Hen egg & {$[24]$} \\
Lysozyme & Hen egg & {$[25]$} \\
Glycinin, $\beta$-conglycinin & Soy bean & {$[26,27]$} \\
Concanavalin A & Jack bean & {$[28]$} \\
Phaseolin & Kidney bean & {$[29]$} \\
Glidin/glutenin & Wheat gluten & {$[30,31]$} \\
Vicilin & Mung bean, red bean, kidney bean & {$[32]$} \\
Congossypin & Cottonseed & {$[33]$} \\
Cystatin & Chickpea & {$[34]$} \\
Not determined & Green pea & {$[35]$} \\
Globulin & Rice bran & {$[36]$} \\
Phloem protein 16-1 & Arabidopsis thaliana & {$[37]$} \\
\hline
\end{tabular}

\section{Sources for PNFs and their structure}

\subsection{Sources}

In principle, PNF-based materials and composites could be made from all three classes of fibril forming proteins, that is, disease-related, functional amyloid, and PNFs without connection to disease or function. The studies of protein fibril formation in vitro started with disease-related proteins with the purposes of simplifying the complex in vivo environment, understanding the physicochemical mechanisms of amyloidogenic proteins fibrillation, and finally finding proper therapies for the associated disorders [41]. There are indeed examples of materials made from in vitro produced disease-related human proteins [42-44] but such structures should be approached with care. Although there is little evidence of any risk of infection by in vitro prepared fibrils, the knowledge about the pathogenic processes related to amyloid fibrils is still limited.

Moving from human proteins, to, for example, yeast, bacteria or plants, or even other mammalian proteins, should in general reduce the risks. Natural functional PNFs from, for example, yeast or bacteria have the advantage that the expression in the host has been evolved, which could facilitate the production. Examples of application of functional amyloid in designed materials include strong underwater adhesive [45] and biosensors [46]. These organisms could also be used for the recombinant production of any PNF-forming protein. 
In order to achieve large-scale production of PNFs, it is desirable to move to proteins from large-scale resources. The finding over the last 10-15 years has presented several options (Table 3); for example, from cottonseed [33], soybean [26], cow milk $[18,47]$, egg [25], and fish industry waste [23]. None of these proteins is connected to any function or malfunction but still form PNFs with similar structures as the classical amyloid proteins. Of special interest are the protein fibrils grown from industrial by-products such as whey protein from cheese factories, which may lead to new applications for these products. Another interesting alternative is synthetic short peptides (less than 20 amino acid residues). Many of these have been shown to form PNFs. They could be designed to possess the desired self-assembly properties and include specific functional groups $[35,48]$.

\subsection{PNF structure}

For many years, the only structural information about PNFs came from imaging techniques like transmission electron microscopy (TEM) and AFM [49,50]. In these techniques, the PNFs appear as long, unbranched fibrils with 5-10 nm width and up to several micrometers length. However, the situation has changed significantly during the last 10-15 years mainly due to the fast development of methods such as solid-state nuclear magnetic resonance (NMR), site-directed spin labeling, simulations, and most recently cryo-electron microscopy. The success in growing crystals from small peptide fragments that possess key characteristics of protein fibrils but still are amenable to single-crystal X-ray diffraction analysis has also been a key achievement for the molecular perspective of PNF structures [3,51]. Through the investigation of PNFs formed from a large number of different peptides/proteins (although most of them disease related), scientists found that PNFs share a common "cross- $\beta$ " spine, which comprises a set of $\beta$-sheets laying parallel to the fibril axis; each sheet is formed from extended $\beta$-strands aligned perpendicularly to the axis. The repeating $\beta$-sheet structure gives rise to a typical $X$-ray fiber diffraction pattern, with a reflection at $8-11 \AA$ corresponding to the intersheet distance (Fig. 2A) and a reflection at $4.8 \AA$ referring to the interstrand distance (Fig. 2B) [50]. One strand is hydrogen bonded to the neighboring strands through backbone amide and carbonyl groups with the bond parallel to the fiber axis. The sheets are stacked in register, that is, the backbone and side chains are on top of one another along the fibril axis. As a result, the pair of sheets in one protofilament tightly interdigitate with each other like a steric zipper and create two different interfaces: dry (the interface between the two sheets without any water molecules) and wet (the interface between protofilaments, which is around the two sheets, surrounded by water molecules) (see Fig. 2C $[52,53])$. The hydrophobic center of the protofilaments as well as its interdigitated $\beta$-sheets structure explains the stability and persistence of protein fibrils. The steric zipper arrangement shown in Fig. $2 \mathrm{C}$ is one common class for steric zippers, named as "face to face," but several other arrangements have been observed [51]. In general, many proteins shows more than one possible steric-zipper structures in their fibrillar form [54], which are referred to as conformational polymorphism [55]. 
(A)

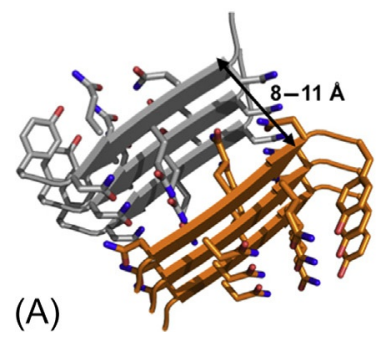

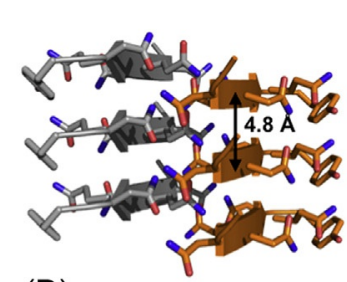

(B)

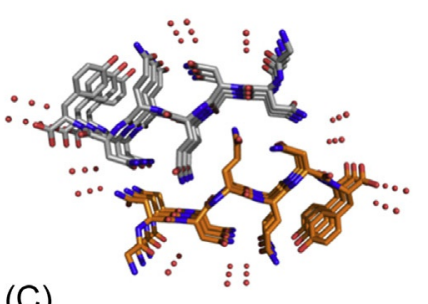

(C)

FIG. 2

X-ray crystal structure of the peptide GNNQQNY (PDB ID: 1yjp [52]): (A, B) A pair of $\beta$-sheets constitute the PNF core structure (the $\beta$-strand backbone is illustrated as bold arrows). The interstrand distance of $4.8 \AA(B)$ and intersheet distance of 8-11 $\AA(A)$ are the features of the typical "cross- $\beta$ " structure. (C) Illustration of the "steric zipper" packing of peptide sidechains. The wet interface is around the pair of $\beta$-strands and the dry interface refers to the region between the sheets. Crystallographic water molecules are shown as small spheres.

Polymorphism can also occur at other structural levels relating to the number and/or the packing of protofilaments in the nanofibrils (Fig. 3).

Although the understanding of detailed molecular structure of PNFs is continuously improved, their mesoscale traits remain less well understood, mainly because

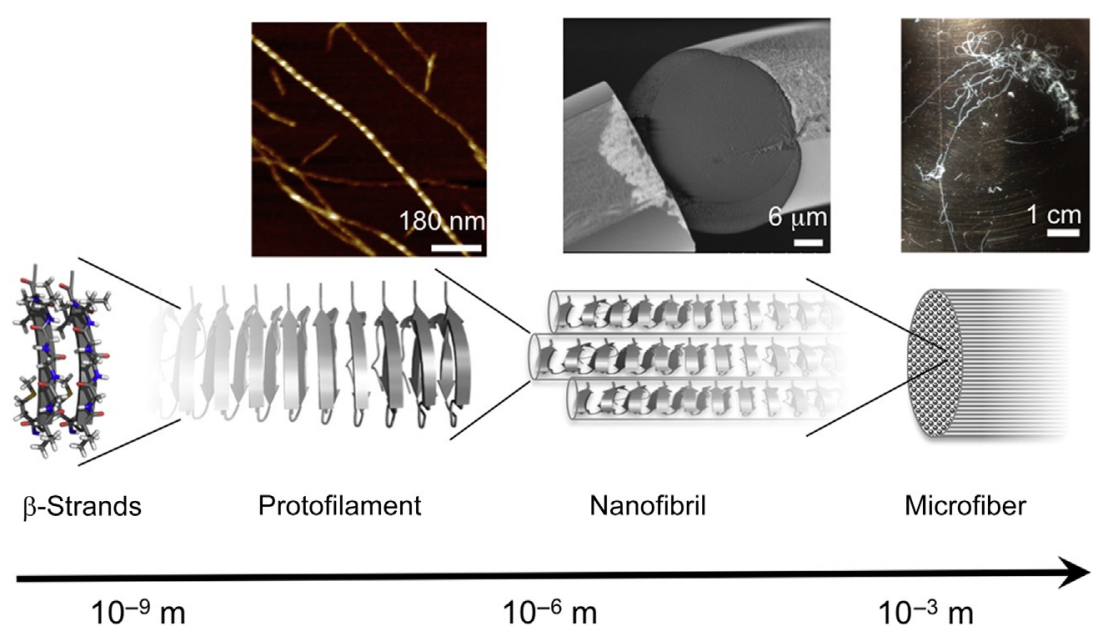

FIG. 3

Illustration of the hierarchical structure of materials made from protein nanofibrils. The $\beta$-strands of the polypeptide chains form the $\beta$-sheets of the protofilaments. A few protofilaments assemble into nanofibrils, which can then be used to create micro- or macroscale materials, for example, fibers. The images in the upper part of the figure have been obtained by AFM (left), SEM (middle), and optical microscopy (right). The scale below the figure shows typical length scales of the illustrated elements. 
of the various amyloid cross- $\beta$ structures and diverse observable polymorphs, which make them recalcitrant to detailed structural analysis. However, some general features have been observed at mesoscale. The cross- $\beta$ structures grow into mature amyloid fibrils via the formation of protofilaments, which are the simplest building blocks of mature fibrils. The protofilaments can consist of, for example, pairwisestacked helical $\beta$-sheets. The fibril morphology depends on the number of protofilaments it contains and how they are arranged. With only a few filaments present, the amyloid fibril tends to have a twisted ribbon structure, due to the planar packing of intertwined filaments, as observed through the cross section. The helical pitch of the twisted ribbon structure is observed to increase with the number of protofilaments in the fibril. With increasing number of filaments the fibril forms a helical ribbon structure (having a lengthwise more uniform diameter/cross section), which can further grow into hollow nanotubes. Fig. 3 shows the structures of PNFs at different length scales.

\section{Production of PNFs}

Amyloid-like nanofibrils can form under a variety of conditions with large variations in the fibrillation kinetics. The same protein can also assemble into fibrils with different molecular structures and/or nanoscale morphologies (polymorphism). The morphology is coupled to the nanomechanical properties of the PNFs [56], and can also affect the mechanical features of macroscopic materials assembled from them [57].

The formation of PNFs most often requires partial or full unfolding of the native globular protein structure. In general, fibrillation-promoting conditions trigger the complete or partial unfolding of the protein and favor the denatured protein to form noncovalent interactions. This will expose potential amyloidogenic segments in the polypeptide chain. It has been proposed that the native structure is a way for nature to protect the proteins from uncontrolled aggregation and fibril formation. Indeed, some of the most well-known disease-related amyloid proteins are intrinsically disordered (i.e., they lack a well-defined three-dimensional (3D) structure in their native state) which potentially make them more prone to form pathological amyloid structures.

Denaturing chemicals such as urea and organic solvents have been used to promote PNF formation of proteins. This has for instance been demonstrated for $\beta$-lactoglobulin, which is one of the most studied proteins in regard to fibril formation. It can grow fibrils in high concentration of urea [58] and in the presence of alcohols [59]. Another frequently used condition for making nanofibrils is at low $\mathrm{pH}$ and high temperature $[60,61]$. Indeed, several different proteins have been reported to form nanofibrils when incubated at low $\mathrm{pH}$ (ca. 2) and high temperature $\left(70^{\circ} \mathrm{C}-90^{\circ} \mathrm{C}\right)[24,26,28,33,47,60,61]$. The generic fibrillation-promoting conditions is partly related to the uniform positive charge of the protein molecules at low $\mathrm{pH}$, which direct the assembly process into ordered structures rather than disordered 
aggregates. The high temperature favors and accelerates the assembly reaction but also promotes hydrolysis of the protein into smaller peptides, which more easily assemble in an ordered way [62]. The link between hydrolysis and fibril formation has been shown for several proteins [24,31,63-65]. Notably, an aqueous solution at $\mathrm{pH} 2$ and a temperature slightly below $100^{\circ} \mathrm{C}$ can be considered as mild and environmentally friendly production conditions in comparison with many other industrial-scale methods to generate (nano) materials.

\subsection{Protein fibrillation mechanisms}

\subsubsection{Approaches to analyze fibrillation mechanisms}

The full understanding of protein fibrillation requires an understanding of the kinetics and thermodynamics associated with the formation of products and intermediates that can occur during fibrillation. The approaches that have been used to determine the kinetics and mechanism of the fibrillation can be divided into two main categories: kinetic/thermodynamic and empirical approaches. The focus of both approaches is to calculate the rate constants and characterize the microscopic processes (nucleation, growth, etc.) of the overall aggregation process by curve fitting of the available kinetic data. However, the fitting equations used in kinetic/thermodynamic methods have specific physical meaning, whereas the empirical methods are chosen depending on how convenient they are in providing data for curve fitting. The kinetic data can be obtained by several analytical techniques such as thioflavin $\mathrm{T}$ fluorescence, Congo red absorbance, circular dichroism, and light scattering. These physical techniques together with the methods for protein fibril characterization have been reviewed elsewhere $[66,67]$.

\subsubsection{Mechanism models}

To reveal the underlying molecular mechanisms of protein aggregation from macroscopical measurements, a variety of aggregation models were proposed and modified during the past half-century [67]. The most comprehensive/advanced approach today for kinetic data analysis of protein aggregation is carried out within the theoretical framework developed by Knowles and coworkers and implemented in the web-based software, AmyloFit [68]. This approach uses quantitative kinetic assays and global fitting to determine the rate constants for primary nucleation, elongation, and secondary nucleation processes such as fibril breakage and surface-catalyzed nucleation events and saturation steps. The mechanistic models are described in Fig. 4. The dominant nucleation mechanism for the aggregation of a certain protein at certain conditions can be defined by its scaling exponent $(\gamma) \cdot \gamma$ comes from a power law relationship, $t_{1} \sim m_{0}^{\gamma}$, where $t_{1}$ is the time when $50 \%$ of the protein is aggregated, where $\overline{2} \quad \frac{1}{2}$

the initial protein concentration is $m_{0}$. The scaling exponent is treated as the reaction order for each model $[69,70]$.

Primary nucleation and elongation: Oosawa and coworkers [71] found that the rate of filamentous transformation of G-actin to F-actin (a slightly different 


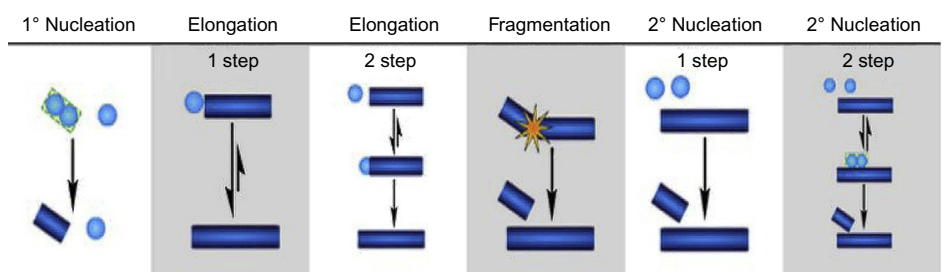

FIG. 4

Mechanisms and models included in AmyloFit.

Reproduced with permission from Springer Nature Customer Service Centre GmbH: Springer Nature, G. Meisl, J. B. Kirkegaard, P. Arosio, T.C. Michaels, M. Vendruscolo, C.M. Dobson, et al., Molecular mechanisms of protein aggregation from global fitting of kinetic models, Nat. Protoc. 11 (2) (2016) 252-272, copyright 2016.

fibrillation process compared to the formation of amyloid-like PNFs) often show two stages: in the first stage, the time-dependent increase in viscosity or birefringence is small and in the second stage, the increase is distinctively faster. These two stages are known as the nucleation/lag and polymerization/elongation, respectively. In this case, a critical nucleus (a minimum sized oligomer) is needed to initiate further elongation, representing the least thermodynamically stable species in solution [72,73]. In the kinetic analysis, Oosawa et al. [71] simplified the assembly of nuclei and the following elongation step as homogeneous nucleation with linear and irreversible growth, and without involving any other protein species. The presented kinetic equations were shown to successfully describe a number of characteristics of in vitro protein assembly phenomena, including the fibrillation of actin and tubulin proteins $[74,75]$.

Secondary nucleation: In the 1980s, further studies of sickle-cell hemoglobin gelation [76] and actin fibrillation [77,78] showed that the early stage of the fibrillation curve was not accurately predicted by the Oosawa theory; the concentration of aggregates in a solution increased faster than expected. In order to account for the observed "extreme autoanalysis" [76-78], it was suggested to include a secondary nucleation pathway (heterogeneous nucleation), which contributes to the increase in reaction rate in addition to the primary homogeneous nucleation [76]. Monomer-dependent secondary nucleation, taking place on the surface of the existing aggregates, can be seen as seeds favoring autocatalytic growth in an alternative view (Fig. 4: $2^{\circ}$ nucleation $1 \mathrm{step}$ ) and it has been shown as a key factor in sickle-cell hemoglobin fibrillation [76]. Monomer-independent secondary nucleation, in the form of polymer fragmentation, was introduced by Oosawa et al. [79] and Wegner et al. [77] as a protein polymerization step. The fragmentation step often exists in the propagation of yeast and mammalian prions and is of great importance for their growth [80,81].

Saturation step: Among the most well-characterized amyloid forming proteins are amyloid- $\beta(1-42)$ and amyloid- $\beta(1-40)$, the major components of senile plaque deposits in patients suffering from Alzheimer's disease. They have been shown to grow fibrils through an autocatalytic nucleation pathway [82,83]. Interestingly, the growth of amyloid- $\beta(1-42)$ fibrils maintained a steady increase in the growth rate 
with a constant $\gamma$ around -1.33 under quiescent conditions. However, amyloid- $\beta$ $(1-40)$ is more complex [82], the $\gamma$-value of amyloid- $\beta(1-40)$ is highly dependent on the initial protein concentration, ranging from c. -1.2 at low concentrations $(5 \mu \mathrm{M})$ to c. -0.2 at high concentration $(60 \mu \mathrm{M})$ [83]. The increase of the $\gamma$-value at higher monomer concentration (saturation behavior) was shown to originate from the multistep nature of secondary nucleation: below a critical monomer concentration, the attachment of free monomers to the fibril surface is rate determining for the generation of secondary nuclei, whereas above this critical monomer concentration, the reaction becomes independent of the concentration of free monomers and is dominated by the conversion and detachment of nuclei (Fig. 4: $2^{\circ}$ nucleation 2 step). This multistep nature has also been observed in the elongation step of the fibrillation processes of various proteins. Similarly, monomeric peptides tend to approach short fibrils for aggregate growth at high monomer concentrations, while dissociation phenomena become significant when the monomer source has been consumed (Fig. 4: elongation 2 step).

Experimental data obtained by ThT fluorescence and light scattering, indicate that fibril formation has several characteristics of nucleation-dependent processes, including a typical lag phase for initial species to grow from denatured proteins, and a following rapid growth phase [84]. However, the lag phase is not always shown in the process. For example, whey protein solutions with initial concentrations ranging from 10 to $80 \mathrm{~g} / \mathrm{L}$ did form fibrils without a distinct lag phase at $\mathrm{pH} 2$ and $90^{\circ} \mathrm{C}$ [65], which was explained by the high protein concentration and high temperature that promote the nucleation process and made it no longer the rate-limiting step. The lag phase is typically shortened or even absent with the addition of fibrils as seeds in a protein solution under aggregation conditions [84, 85].

\subsection{Factors influencing the fibrillation}

Once the fibrillation mechanism has been determined and verified, it can be used to study the specific effect of various factors influencing protein aggregation. First of all, the propensity to form a fibrillar structure can vary dramatically with the sequence of amino acids under the given conditions [86]. Even single mutations in the amino acid sequence can have an effect on the fibrillation rates and mechanisms. The aggregation process and the properties of protein fibrils are highly dependent on several factors, for example, protein concentration, temperature, time, stirring during heating, $\mathrm{pH}$, and metal ions present in the solution. For example, Loveday et al. [87] found that the fibrillation of the whey protein $\beta$-lactoglobulin was accelerated in the presence of metal ions (e.g., $\mathrm{Ca}^{2+}$ and $\mathrm{Na}^{+}$). The resulting gels, which are interesting ingredients as texture modifying agents of food and biomedical products, became more viscous and the protein fibrils became shorter and more bent/ twisted compared to metal ion-free systems. Other studies have focused on using $\beta$-lactoglobulin protein for fabrication of iron oxide $\left(\mathrm{Fe}_{3} \mathrm{O}_{4}\right)$ hybrid materials and applications such as design of functional colloidal system [88]. There have been a number of reviews on protein-NP interactions, discussing, for example, how the 
NP influences protein conformation and how the protein corona can be analyzed $[89,90]$. NPs can act as catalysts for protein fibrillation, by providing a locally increased protein concentration promoting oligomer formation [91].

4 Properties of single PNF

\subsection{Mechanical properties}

Defining the mechanical properties of nanoscale objects is indeed a scientific challenge. Smith et al. [92] measured the fundamental mechanical properties of single PNFs formed from the protein insulin, using AFM and spectroscopy. The twofilament insulin fibrils were deposited onto nanoscale grooves, and force spectroscopy was then performed on the fibrils suspended on a groove (Fig. 5). Based on the force-distance curve obtained from the experiment, the insulin fibrils were shown to have a strength of c. $0.6 \mathrm{GPa}$, which is as high as that of steel, and a stiffness (c. $3.3 \mathrm{GPa}$ ) comparable to silk. The rigidity of fully formed PNFs from different resource was shown to vary over four orders of magnitude. The mesoscale structures of the fibrils should be responsible for this, at least partially. Usov et al. [93] analyzed the mechanical properties via the theory of elasticity. Instead of considering the single PNF as a rod/tube, they demonstrated that considering the influences of the energetic contributions of the different fibril morphologies (twisted ribbons, helical ribbons, and nanotubes) provides a more accurate approach to describe the mechanical properties. The authors established a detailed resolution of the moment of inertia for nonaxisymmetric fibrils. For instance, twisted ribbons composed by two protofilaments showed a modeled elastic modulus in the range of 1.4-3 GPa, which is in accordance to experimental data for bovine serum albumin. An increase in the number of the protofilaments for twisted ribbons gives rise to an increase in the Emodulus to c. $4 \mathrm{GPa}$ (using $\beta$-lactoglobulin as reference fibril). Similarly, the elastic moduli for other mesoscale structures, that is, helical ribbon and nanotubes, where successfully modeled by Usov et al. and correlated well with experimental values. However, all the fibrils with different morphologies were proved to share the similar

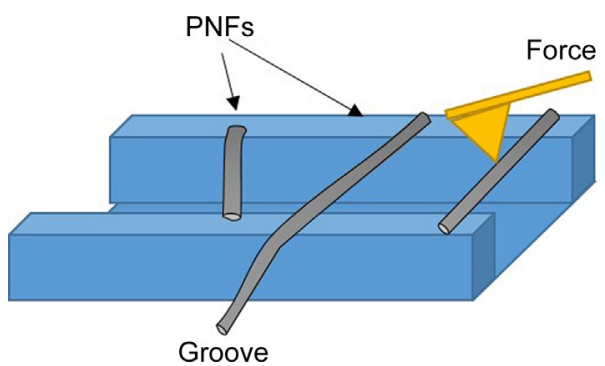

FIG. 5

The mechanical test on a single insulin fibril on a groove. 
intermolecular interactions that stabilize these rigid fibrils and give a high elastic modulus. The contribution to the rigidity mainly comes from the hydrogen-bonding network in the generic cross- $\beta$ core. The side-chain interactions can additionally influence the rigidity by stabilizing/destabilizing the basic cross- $\beta$ core structure [56]. The high strength and stiffness contribute to the stability of the protein fibrils to some extent, which on the other hand make the PNFs harder to degrade compared to the nonfibrillar protein itself. Protein fibrils resemble spider/moth silk in terms of structure and mechanical properties; however, they are superior to silk considering the production process as silk needs a complex biological living system to produce while PNFs can be easily produced in laboratory under appropriate conditions.

\subsection{Optical properties}

PNFs have been found capable of emitting fluorescence in the visible wavelength range of light during their aggregation. It has been demonstrated that the fluorescence (which last several nanoseconds) originates from the folding of cross- $\beta$ sheet scaffold, and the intensity of the observed fluorescence corresponds to the extent of aggregation in protein solutions. In other words, the fluorescence signature appears to be a promising approach to assess the formation of PNFs without requiring additional fluorescent probes [94]. However, the intrinsic fluorescence is also likely to be affected by potential inhibitors that are themselves fluorescent or fluorescence quenchers. In this case, other fluorescent probes are needed to retain high detection sensitivity. Here, it has been widely established that PNFs can interact with several dyes and change their optical properties: Congo red shows a yellow-green birefringence [95]; thioflavin T increases its fluorescence intensity with orders of magnitude [96]; and thiophene-based compounds change their photoluminescent properties [97-99].

\section{PNF materials}

PNFs have been scaled up into macroscopical forms such as hydrogels, films, and fibers (Fig. 6). However, compared to other types of NPs the knowledge about the structure and properties of these materials is still limited. In general, the amyloid-like structure of PNFs stays intact during the scaling process, which allows further functionalization by decorating with different molecules $[57,100]$.

\subsection{Hydrogels}

Most examples of upscaling of PNF-based materials are on hydrogels, in particular from food-grade protein sources [101] and synthetic short peptides [102]. During the heat-induced self-assembly of proteins, the PNFs solution becomes more viscous overtime and reaches a gel-like state. The gels, produced from a $10 \mathrm{wt} . \%$ whey protein isolate solution, have a storage modulus of c. $100 \mathrm{kPa}$ [103], and for a $5 \mathrm{wt} \%$ 


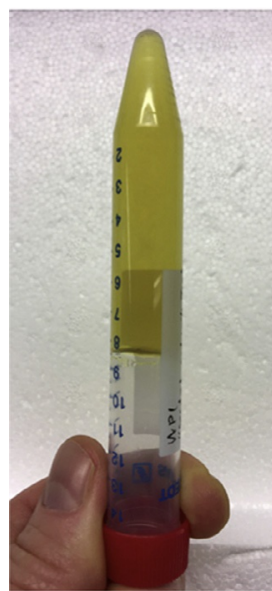

(A)

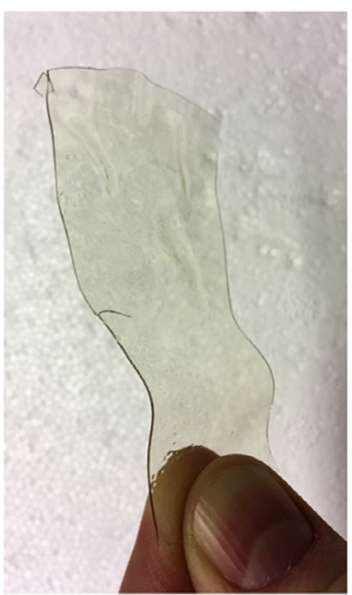

(B)

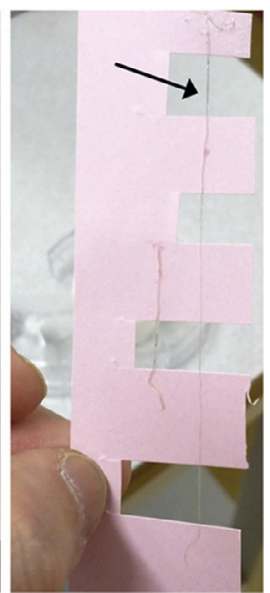

(C)

FIG. 6

Materials made from whey PNFs. (A) Hydrogel functionalized with ThT, (B) protein/protein nanocomposite film, and $(C)$ fiber spun by flow focusing (kindly provided by Eirini Ornitopoulou).

solution, the storage modulus is $10 \mathrm{kPa}$ [104]. The gelation ability of PNFs can be ascribed to their high aspect ratio and their ability to form entangled networks [105].

Apart from the typical heat-induced gelation, Veerman et al. [106] developed a multistep cold-set gelation, where two extra steps were added after the formation of PNFs: a pH neutralization and the addition of salt ions as a cross-linker. The additional cations screen the electrostatic repulsion between PNFs and provoke aggregation of fibrils [107]. Therefore, the critical gel concentration decreases with an increasing ionic strength [108]. With the help of the cations, the protein solution can form gels at very low protein concentration (2 wt.\%) [103,106,109]. Several different salts have been used for cold gelation; divalent cations were shown to have a better ability to build bridges between PNFs and a higher efficiency for fabrication of gels compared with monovalent cations [104]. $\mathrm{Zn}^{2+}$ gave a firmer (firmness: $0.66 \mathrm{~N}$ ) and a more compact gel with a higher water holding capacity $(97 \%)$ than when using $\mathrm{Mn}^{2+}$ and $\mathrm{Ca}^{2+}[110]$. Although the presence of salt enhances the gelation ability of PNFs, side effects are also reported [111]. The ions influence the rate of bacterial growth and the physicochemical properties of the protein molecules, which are important factors for PNFs gels as carriers of bioactive ingredients. An alternative way of provoking gel formation without adding cations is through dialysis. An ash-free whey-PNF gel was created through a deacidification step by slow dialysis against water [112]. The ejection of hydronium ions increased $\mathrm{pH}$ toward the isoelectric point of the protein and diminished the repulsion between PNFs, which activated the formation of the gel. The obtained gel was shown to have a higher storage modulus and fracture strength over the $\mathrm{Ca}^{2+}$-induced gel. 


\subsection{Films}

In a pioneering work, Knowles et al. [100] prepared PNF films from lysozyme and $\beta$ lactoglobulin nanofibrils by a casting process. The films were shown to have a nematic structure in the presence of plasticizers (glycerol or polyethylene glycol). It is likely that the plasticizer in the films enables the liquid-crystalline behavior of PNFs in solution [113] to remain in the solid phase by interfering with the interfibril interactions. The developed highly ordered PNF films show that it is possible to control the organization of objects (e.g., fluorophores) that cannot form oriented structures on their own. It has also been shown that the high rigidity of PNFs is preserved in produced films [100], which is promising for the production of highperformance PNF films, as the upscaling in size generally leads to poorer mechanical properties. For example, the "bucky paper" formed from carbon nanotubes has an elastic modulus and tensile strength several orders of magnitude lower than that of individual carbon nanotube [114]. To maximize the alignment/orientation in PNF films, Bäcklund et al. [115] produced PNFs with a high average length and with low content of spherulites (which are spherical protein aggregates originating from an amorphous protein nuclei) by stirring the solution only in the early fibrillation stage. In this way, PNFs produced had an average length of $7 \mu \mathrm{m}$, which is higher than that of PNFs generated from continuous stirring $(3 \mu \mathrm{m})$. The yield of fibrils relative to spherulites was also increased compared to that in quiescent conditions. Accordingly, the films made in the case of limited stirring had a higher degree of alignment, as determined by the degree of polarization of emitted light from Nile red dye incorporated in the PNF solutions.

Courchesne et al. [116] made films of PNFs produced from Escherichia coli bacteria by a purification process using vacuum filtration. The method did not sacrifice any functionality of the PNFs, which provided an easy and cheap way to obtain sufficient quantities of recombinant protein to fabricate macroscopical materials. Recently, it has been reported that a plasticized whey PNF film has a better homogeneity, transparency, water barrier properties, and antioxidant activity than nonfibrillar protein films, which makes it a possible candidate as edible films/coatings for food products [117].

\subsection{Fibers}

Kamada et al. [57] made microfibers using a flow-focusing setup without using any additives. PNFs were assembled into closely packed graupel-like units in fibers of a few hundred nanometers in diameter, which had a smooth and uniform cross section. The microfibers were shown to have a stiffness in the same range as of individual PNFs, while the strength did not reach the expected values of PNFs. Surprisingly, among the two different nanofibril morphologies that were studied, the PNFs with higher degree of alignment resulted in weaker microfibers, which is opposite to what is observed in many other systems (e.g., cellulose nanofibrils) [118]. One possible explanation is that the fibers produced by the method possess either high fibril 
alignment (straight fibrils) or good interfibril bonding/entanglement (curved fibrils) instead of both features. A stronger fiber requires a combination of ordered nanostructure and fibril entanglement. Other scientists [119] used an anionic polysaccharide as cross-linker to improve the interfibrillar bonding of hen egg white lysozyme PNFs, an attractive candidate material for tissues and cellular scaffolds. The resulting fibers, with calcium phosphate mineral crystals oriented along the nanofibrils, obtained a ninefold increase in fiber stiffness while the strength of the fiber remained the same as for the individual fibrils.

\section{Nanocomposites with PNFs and possible industrial applications of these}

PNFs, assembled from proteins or small peptides, contain various functional groups (e.g., $-\mathrm{COOH},-\mathrm{SH}$, and $-\mathrm{NH}_{2}$ ) that allow for chemical modification and often for improved affinity to other materials $[45,120]$. This feature combined with their good mechanical properties (as nanofiller) and high aspect ratio (as template), enable various natural/artificial functional nanocomposites for multiple applications to be obtained [6]. Functional PNF composites have been successfully produced with carbon nanomaterials, metal NPs, organic compounds, and peptides to obtain largersized materials with specific properties.

\subsection{PNFs as filler}

One-dimensional (1D)/fibrous nanomaterials, due to their high aspect ratio and often good cohesion to the matrix (providing efficient stress transfer between the matrix and the filler), are frequently used to improve the mechanical properties in composites. Carbon nanotubes are popular components for this purpose because of their high stiffness with a Young's modulus of $1 \mathrm{TPa}$ [121]. PNFs display lower modulus, but are more hydrophilic in comparison to carbon nanomaterials, which make them easier to disperse in aqueous solutions. Noteworthy is that the use of PNFs from hen egg white lysozyme improved the stiffness of a silicone elastomer to a level twice that obtained with the use of carbon nanotubes at the same content [122]. The improvement in stiffness is also impressive in other PNF-containing nanocomposite. For example, with $0.6 \mathrm{wt}$.\% of bovine insulin fibrils, a PNF-poly(vinyl alcohol) composite became $15 \%$ stiffer than the fibril-free poly(vinyl alcohol) material [123]. These mechanical changes are often accompanied by desired or undesired changes in microstructure, morphology, and thermodynamic properties [123-125]. For example, a decrease in the glass transition temperature was observed in the poly(vinyl alcohol) case above. Hence, to obtain an improvement of the overall thermomechanical properties, further modifications are need for such materials as well as the fabrication processes [122].

An attractive approach is to improve the properties of protein-based materials by protein fibers and PNFs from the same source/raw materials (Fig. 7) [125,126]. 


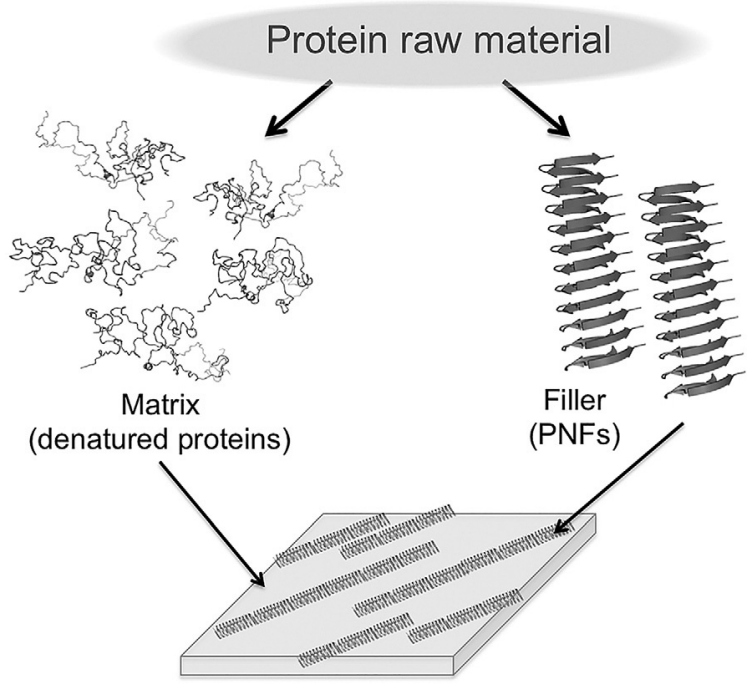

FIG. 7

A protein/protein nanocomposite based on PNFs and matrix from the same protein raw material.

Recently, this concept was investigated in plasticized whey protein films. The modulus of the PNF-containing protein films was approximately twice that of the nonfibrillar protein films at a PNF content of $15 \mathrm{wt} . \%$. At the same time, extensibility decreased, but to a level where the film was still ductile [125]. The $\beta$-sheet structures were preserved in the composites, which allows for further functionalizations.

\subsection{Composites with carbon nanomaterials}

Carbon nanomaterials (fullerene, carbon nanotubes, and graphene) are a popular class of nanofiller for biological materials. In addition to the reinforcing effect, they add other desirable features to the final materials such as near-infrared response, antiviral activity, and conductivity [127,128]. However, their poor solubility is one of the main limitations for a wider use in biological materials. In this case, the hybridization of PNFs and carbon nanomaterials gives a new solution to improve the biocompatibility of carbon materials and lead to a series of strong and multifunctional biomaterials [129].

One example is graphene showing a more stable suspension in water solutions with the help of PNFs from $\beta$-lactoglobulin attached to its surfaces through electrostatic interactions. The graphene-PNF composite films, prepared through vacuum filtration of a graphene-PNF colloidal dispersion (Fig. 8), were able to absorb water with an expansion ratio that was proportional to the PNFs content [130]. By increasing the content of PNFs, the composite films exhibited a perfectly reversible 

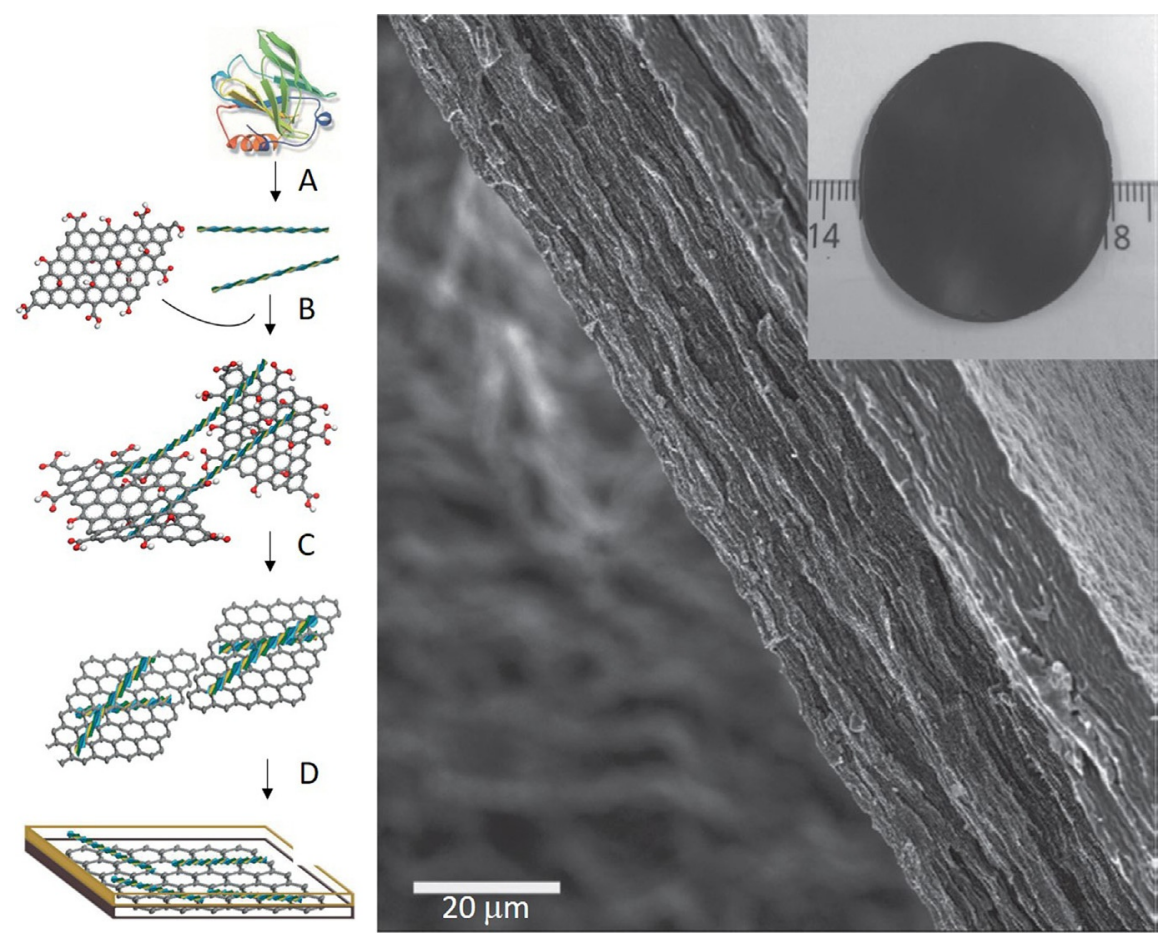

FIG. 8

Illustration of the formation of PNF-graphene nanocomposites. The fabrication started with the self-assembly of $\beta$-lactoglobulin nanofibrils at $\mathrm{pH} 2$ and $90^{\circ} \mathrm{C}(\mathrm{A})$, thereafter, during mixing, electrostatic interactions takes place between the fibrils and the graphene oxide (GO) flakes (B). Broken fibrils bond to graphene after $\mathrm{GO}$ reduction $\left(T=80^{\circ} \mathrm{C}\right)(\mathrm{C})$. The final structure is obtained by vacuum filtration (D).

Reproduced with permission from Springer Nature Customer Service Centre GmbH: Springer Nature, C.L. Li, J. Adamcik, R. Mezzenga, Biodegradable nanocomposites of amyloid fibrils and graphene with shape-memory and enzyme-sensing properties, Nat. Nanotechnol. 7 (2012) 421-427, copyright 2012.

geometry response to changes in humidity, which could be used in, for example, biosensors. Furthermore, these well-defined layer-by-layer composite films (Fig. 8) also integrated the advantages of the two materials such as good mechanical properties and high conductivity (reaching $0.51 \mathrm{~S} / \mathrm{cm}$ ) of graphene and the enzymatic degradability of PNFs. The properties were also tunable by changing the graphene/PNFs contents. For example, the conductivity of the nanocomposites could be changed by the digestion of PNFs with the presence of porcine gastric enzyme. The fluctuation of the conductivity was used for the estimations of enzyme activity. The same group also explored a similar composite with the graphene sheets replaced with hydroxyapatite platelets. The idea was to use $\beta$-lactoglobulin fibrils to mimic natural collagen fibrils in bone tissue and to create a new material whose Young's modulus 
resembled that of real bones [131]. The PNF-hydroxyapatite material showed a Young's modulus that was closely related to the content of PNFs. By optimizing the fibril content, the hybrid material exhibited a Young's modulus that was comparable to the modulus of natural cancellous bone.

Li et al. [132] designed a pH-responsive PNF-carbon nanotube hydrogel, taking advantage of the neutral PNFs (being at or close to the isoelectric point). Multiwall carbon nanotubes were negatively charged by a high content of $\mathrm{SO}_{3}{ }^{-}$ions covalently/noncovalently connected to the nanotubes. At a pH below the isoelectric point of the protein, PNFs were positively charged and the carbon nanotubes, with negative charges reduced the electrostatic repulsion between the PNFs and activated the gelation as a cross-linker. Rheology data showed that the material has a gel-like behavior. At a $\mathrm{pH}$ above the isoelectric point, however, the material was liquid like. Pure PNFs gels are seldom able to respond to $\mathrm{pH}$, since aggregation is generally an irreversible process [133].

\subsection{Composites with metal/metal oxide}

As mentioned earlier, metal ions can speedup fibril formation and gelation processes, which indirectly demonstrate the metal binding ability of PNFs. The binding capacity of $\beta$-lactoglobulin PNFs was investigated by Bolisetty and coworkers $[134,135]$. They found that the PNFs possess effective binding sites for various metal ions and those metal ions can be reduced to NPs/crystals by the addition of reducing agents. This unique property has been considered for different applications.

One typical example is water purification membranes for the removal of heavy metal ions $[134,135]$. Activated carbon was added to provide mechanical support to a membrane with $\beta$-lactoglobulin nanofibrils and to increase the available membrane active surface area. The membranes were shown to efficiently remove typical metal pollutants $(\mathrm{Au}, \mathrm{Hg}, \mathrm{Pb}, \mathrm{Pd}$, and $\mathrm{As}$ ) and radioactive wastes (uranyl acetate and phosphorus-32) from contaminated water even after several runs. The trapped ions can be recycled trough thermal reduction and purification processes. In addition to purification membranes design, the same research group built a hybrid PNF-metal membrane for the purpose of continuous flow catalysis (Fig. 9) [136]. Gold and palladium NPs were attached to the sites via chemical reduction processes and the catalytic property of the created membranes was assessed for the reduction of 4-nitrophenol into 4-aminophenol. It was shown that the deposition of particles on the fibrils enhanced their catalytic efficiency and that, for the case of this particular reaction, the complete conversion was achieved within a single flow through the membrane. PNF scaffolds were also used to transfer metal NPs in living cells [137]. The $\beta$-lactoglobulin nanofibrils acting as a vehicle for gold, palladium, and silver NPs provided a better NP penetration. The penetration of gold NPs was increased by up to three times compared with pure particles. It was observed that silverPNF hybrid materials showed a high cytotoxicity toward dendritic and MCF7 breast cancer cells, and the transfection of silver NPs was enhanced when associated with PNFs. This experiment shows the potential for cancer treatment and, more generally, 


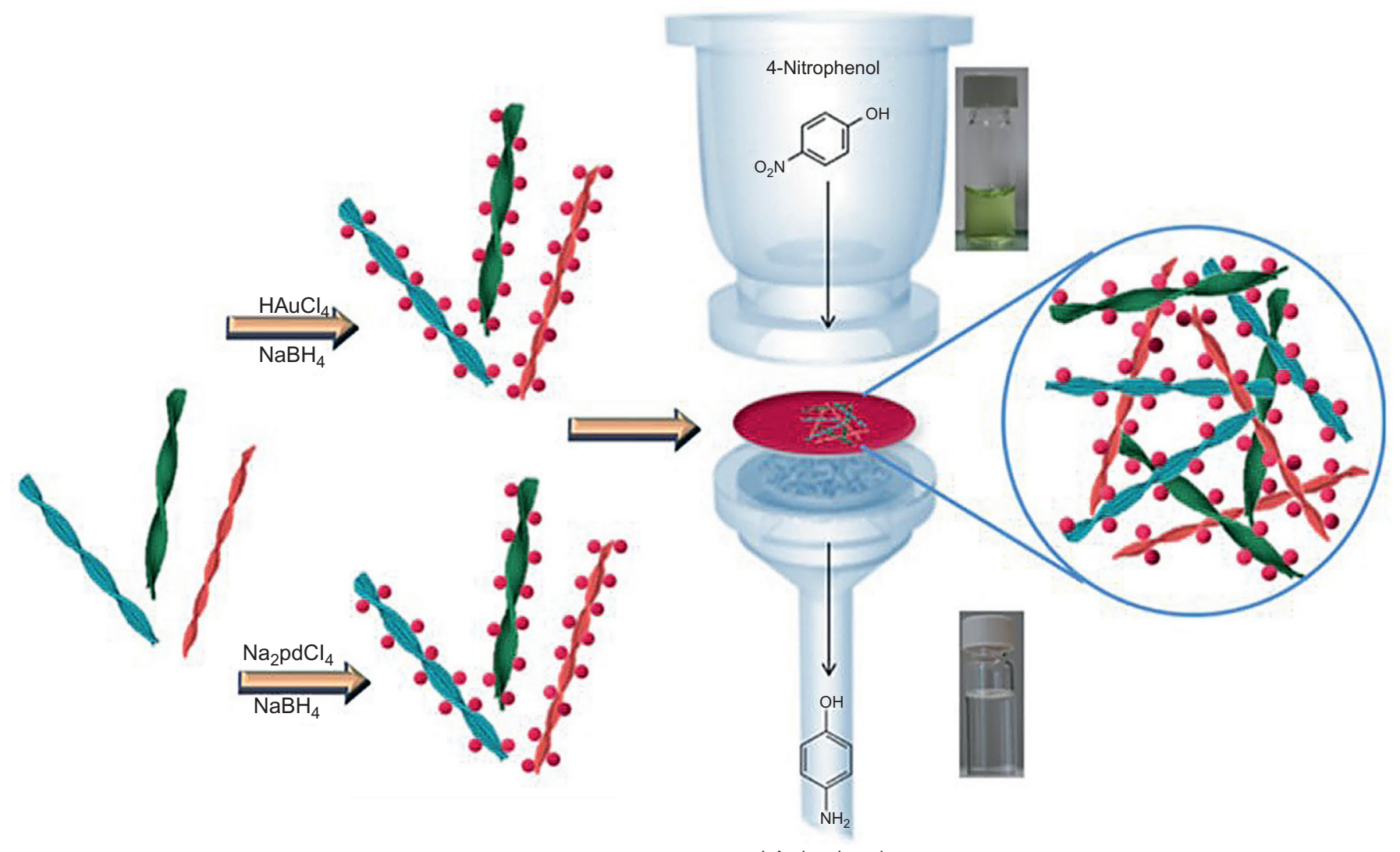

4-Aminophenol

FIG. 9

Catalysis membrane setup.

Reproduced with permission from S. Bolisetty, M. Arcari, J. Adamcik, R. Mezzenga, Hybrid amyloid membranes for continuous flow catalysis, Langmuir 31 (51) (2015) 13867-13873. Copyright 2015, American Chemical Society. 
the application opens a new way for targeted therapeutic agents in living organisms, provided that the agent can be bonded to PNFs.

Except for the binding properties, PNFs from $\beta$-lactoglobulin [138] and lysozyme [139] have been shown to assist in the synthesis of micro-sized gold crystals as a templating, reducing, and stabilizing agent. The gold crystal-PNF composite was shown to have plasmon and fluorescence features [138]. It was observed that it is possible to control the size of gold crystal plates by tuning the ratio of the content of gold salt and PNFs. When the concentration of $\beta$-lactoglobulin nanofibrils was above the isotropic-nematic transition, gold single-crystal platelets and PNFs assembled into stacks in a new hierarchical sandwich-like structure. The planar area of gold microplates could be increased to $10^{4} \mu \mathrm{m}^{2}$, which is considerably larger than the area of the gold plates made without PNFs $\left(10^{2} \mu \mathrm{m}^{2}\right)$ [140-142]. By obtaining the gold plates with larger surface area, solid composites with these turned out to have a conductivity switch effect that was very sensitive to the actual mechanical strain of the material and should therefore be possible to use for sensing things such as the bending of a finger or small variations in air pressure [143]. The gold-PNF colloidal suspension was further vacuum filtered into hybrid films, similar to the production of graphene-PNF films shown in Fig. 8 [144]. These hybrid films, with alternating gold crystal platelets and PNF layers, are promising candidates for humidity and $\mathrm{pH}$ sensors, due to their changes in conductivity and plasmon resonance, respectively. The gold-PNF suspension was also made into aerogels through a sol-gel approach and a drying process using supercritical $\mathrm{CO}_{2}$ [143]. These aerogels retained the percolation and fluorescence features and showed higher compression resistance than the traditional silica aerogels. In addition, the aerogel exhibited different colors and morphologies depending on the actual structure of the gold (spherical NPs or crystal plates).

Due to the high aspect ratio of PNFs, PNFs have been used as templates in the formation of nanowires $[145,146]$. Short diphenylalanine peptides can self-assembly into discrete and stiff nanotubes with a diameter less than $300 \mathrm{~nm}$ and a length of up to few micrometers. Reches and Gazit [145] filled the nanotubes with silver salt solutions and reduced the silver ions by sodium citrate. The silver nanowires were then prepared by enzymatic digestion of the peptide template. The same procedure was used by Malisauskas et al. [146]. However, instead of building on a nanotube template of diphenylalanine, they used the PNFs from lysozyme as templates, which were in average thinner than the nanotubes from diphenylalanine. Hence, the diameter of the resulting silver wires could be as thin as $1 \mathrm{~nm}$.

In another approach, in order to assist in the orientation of $\beta$-lactoglobulin, negatively charged $\mathrm{Fe}_{3} \mathrm{O}_{4}$ NPs were mixed with positively charged fibrils and orientated in a magnetic field. The alignment of the hybrid fibrils depended on the flexibility, aspect ratio, magneto-responsiveness, and the magnetic strength of the introduced field [147]. As the $\mathrm{Fe}_{3} \mathrm{O}_{4}$ particles were directly mixed with the $\beta$-lactoglobulin protein solution, it was also possible to control the morphology of the hybrid aggregates by changing the $\mathrm{pH}$ and temperature during the synthesis of the PNFs [88].

Shen and coworkers [148] introduced $\mathrm{CaCO}_{3} \mathrm{NPs}$ in a network of $\mathrm{Ca}^{2+}$ ions and $\beta$-lactoglobulin nanofibrils to increase the gel strength of the new PNF-CaNP gels. 
Two orders of magnitude higher than the original gels were observed, that is, comparable to the strength of human tissue. The hybrid gels with a short gelation time (c. $75 \mathrm{~s}$ ) were also shown to have $\mathrm{pH}$-induced self-healing properties.

\subsection{Composites with organic molecules-Optoelectronic materials}

Among the earliest recognized features of amyloid-like PNFs was the ability to interact with the dye Congo red and thereby alter its photophysical properties [95]. The birefringence observed for Congo red bound to protein deposits is still used as a diagnostic tool for the presence of amyloid structures. The ability of PNFs to align and organize dyes as well as luminescent or conductive polymers has been explored with the aim to create optoelectronic materials. Herland et al. [149] built luminescent nanowires by integrating oligoelectrolytes into insulin nanofibrils, whose electrooptical properties could be controlled by electrochemical doping. Hamedi et al. [150] grew organic nanowires with alkoxysulfonate poly(ethylenedioxythiophene) known as PEDOT-S aligned along the fibril axis on the surface of insulin PNFs. The condensed nanowire networks can be placed between two electrodes and used as electrochemical transistors.

Most conductive or fluorescent polymers are hydrophobic while PNFs form and disperse typically in aqueous solutions. This makes it difficult to find systems where both components mix readily. To solve this problem, Solin and Inganäs [151] proposed two different methods to build organic polyelectronic materials. In one of these, the functional polymers are connected to protein monomers before the fibrillation process. In this way, with proper conditions, the protein monomers selfassemble into PNFs resulting in a hybrid material without any hindrance from the incorporated polymers. This method should be possible to apply to most PNF materials, especially those that are insoluble in water, since those materials can be dry mixed with the protein matrix by first grinding both components. One example is hydrophobic iridium complexes, which are powerful emitters for organic lightemitting diodes. The fabrication process started by grinding insulin and two different iridium complexes, followed by the self-assembly of insulin in aqueous solution resulting in light-emitting PNF-iridium complex hybrids having different colors [152]. To take the process one step further, Rizzo and coworkers [152] blended insulin fibrils mixed with yellow and red dyes into a blue-emitting polyfluorene host, thus producing white light-emitting diodes. The presence of PNFs led to improved luminescence and higher external quantum efficiency in comparison to pure Ircomplexes.

The other method starts with mature PNFs, which are then functionalized with conductive/fluorescent polymers (Fig. 10). This method is more suitable for water-compatible polymers, such as poly(thiophene acetic acid) Li [154], polyfluorene (PPF) [155], and alkoxysulfonate poly(ethylenedioxythiophene) known as PEDOT-S [150]. This strategy results in a core-shell architecture with the PNFs being the core and the functional polymers being the shell. PPF-coated insulin nanofibrils, generated with this method, were built into an active layer of a light-emitting 

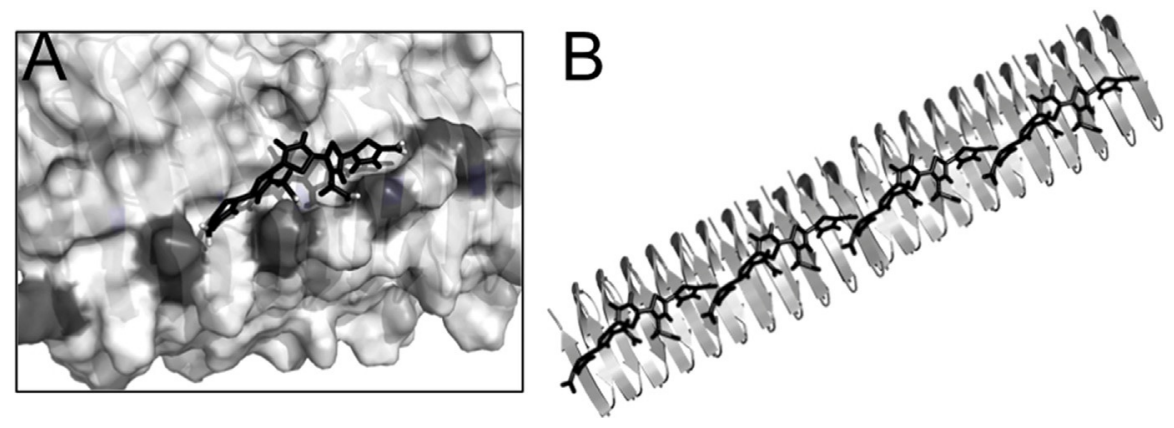

FIG. 10

Binding of organic molecules (luminescent conjugated polythiophene) to PNFs. (A) A molecular view of the binding mode of the polythiophene to PNFs from the protein HET-S (PDB ID: 2mus [153]). Positively charged groups on the PNFs are indicated by black color. (B) Illustration of long-range alignment of the polythiophene molecules through the interaction with the PNF scaffold.

diode. The device, emitting blue light, showed an external quantum efficiency 10fold that of the sole PPF device, which can be explained by the enhanced electron injection and balanced charge-carrier mobility in the hybrid device originating from the alignment of PPF [156].

In these examples, optoelectronic PNFs became better dispersed and more stable in aqueous solution, in other words, the amphiphilic PNFs can be seen as a dispersing agent for hydrophobic optoelectronic polymers in aqueous solutions. This has been utilized by Bäcklund [157] to create a stable colloidal oligothiophenes suspension serving as a source of oligothiophenes ready for fabrication of electronic devices in aqueous solutions. The oligothiophene was also aligned parallel to the fibril axis and exhibited polarized light emission. Similarly, PNFs from lysozyme were utilized as template for the formation of linear polyaniline through a polymerization process that made the preparation of nanowires in aqueous solution possible [158]. Aniline monomers were here coated on the surface of PNFs with hydrophobic interactions; the polymerization of the monomers resulted in a conductive outer layer, enclosing the PNFs core. With the presence of PNFs, a stable dispersion was obtained instead of a polyaniline precipitate.

\subsection{PNF materials via protein engineering}

Protein engineering of the monomeric precursors can be used to design not only the fibril-forming segments but also additional parts with specific functionality (Fig. 11). This approach has been explored with potential applications in cell growth, bonemimetic materials [131], biosensors [159,160], NP transfer [137], and drug release [161]. Although some of these materials have already been included in the previous sections, here we highlight a few more examples in this context. 


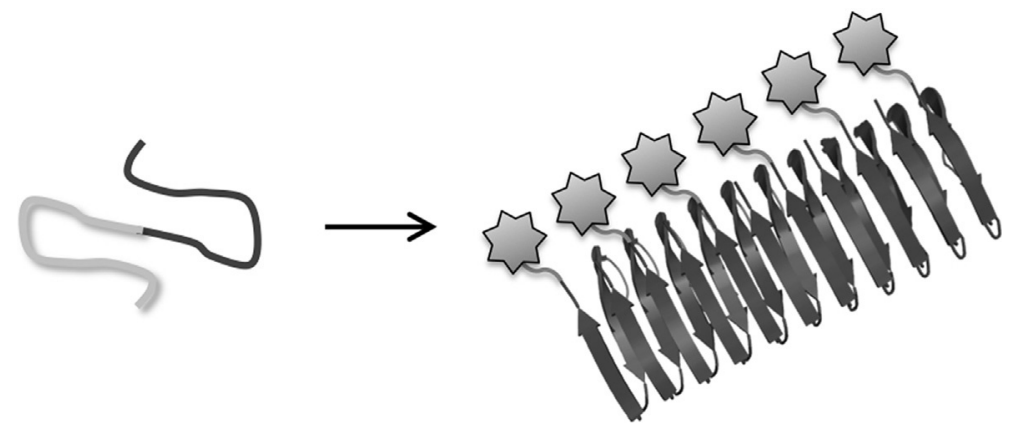

FIG. 11

Fusion proteins with one fibril-forming part (gray) and one functional part (light gray) can be designed by protein engineering methods. Self-assembly of this protein results in PNFs decorated with functional protein units, for example, enzymes or cell adhesion peptides.

As proteins are intrinsically biocompatible, PNFs provide an attractive alternative as components for biopolymer materials. PNFs have been successfully tested as scaffolds for arginine-glycine-aspartic acid and arginine-glycine-aspartic acidserine peptides for improving the adhesion and spreading of cells [43,162]. In the study by Reynolds et al. [163], PNFs networks from self-assembled lysozyme protein were deposited on a mica surface, mimicking the extracellular matrix with plasma layers on top. The culture of fibroblast cells on these composite films showed an increase in cell attachment and spreading rate compared with pure plasma films. In addition, this degree of attachment and spreading can be finely tuned through variation in surface chemistry and nano-topography, in turn, obtained by an optimization of plasma content and incubation time of PNFs during fibrillation [163].

PNFs were also used as a solid support for enzymes to separate them from soluble substrates, which allows enzyme reuse without the necessary postcatalysis purification steps [164]. However, with the presence of PNFs, the catalytic efficiency of enzyme fibrils is 10-50 times reduced compared with the free enzyme $[165,166]$. The reasons for the reduction could be a change of the native folding of the enzyme restricted enzyme diffusion and/or reduced accessibility of active sites due to the dense packing of the enzyme. To avoid this, Schmuck et al. [167] mixed a chimeric protein (that can fibrillate and display the functional domains, TEM1-Ure2(80)) with a carrier protein (normal fibrillation domains, Ure2(1-80)) to lower the packing density of the enzyme. The TEM1 and Ure2(1-80) are selected enzymes from E. coli (capable of antibiotics hydrolysis) and a fibril-forming protein from Saccharomyces cerevisiae, respectively. Later, these enzyme-doped PNFs were trapped in a spin cup filter, similar to the setup for the metal-PNF catalysis membrane in Fig. 9. By doing this, the diffusion process that quenched the catalytic efficiency was replaced by a continuous substrate flow that maintained $80 \%$ of the catalytic turnover rate of TEM1. This enzymatic filter, combined with the PNF-active carbon membrane, 
can be a promising material for a water purification device that efficiently removes antibiotics and metal ions in contaminated water.

The potential of making bifunctional PNFs makes PNFs interesting for various biosensors. Men et al. [46] managed to build an immunoassay by aligning a detector [immunoglobulin $\mathrm{G}(\mathrm{IgG})$ ] and a signal generator [methyl-parathion hydrolase enzyme (MPH)] together on PNFs made of the yeast protein Sup35p. The IgGMPH bifunctional nanowires were simply made by seeding the monomer Sup35MPH solution with short premade short Sup35-IgG fibrils. By controlling the content of the two components, signal molecule to capture molecule ratio could be increased, which yielded an improvement in the device sensitivity compared to the recombinant IgG-MPH system, whose signal/capture ratio was $1: 1$. However, the sensitivity of the biosensor is still lower than the commercial ones due to the low activity of MPH. Later, the authors replaced MPH with a biotin acceptor peptide, which could transfer various diagnostic enzymes to an antigen-antibody complex via the biotin-avidin system and remarkably improve the sensitivity of the biosensors. This biotin-avidin system was also used in other biosensor devices. Chan et al. [168] immobilized DNA probes onto biotinylated PNFs through streptavidin linkers for the detection of cDNA sequences. The detection limit of the novel DNA detector was at subattomole level (183 fM in $10 \mu \mathrm{L})$. The same method was also used by Gerrard's group [169] to generate glucose biosensor, where glucose oxidase (GOx) was attached on whey PNFs through biotinylation. The GOx-PNFs hybrids were then thiolated and placed on gold electrodes, which showed an electric current response when sensing glucose. Again, the sensitivity of the device increased compared to the pure gold electrode and GOx, owing to the biotin-avidin reaction and thiol-metal interaction. Except biotinavidin binding, glutaraldehyde was demonstrated as an efficient cross-linker between PNFs and several enzymes (e.g., GOx, $\beta$-galactosidase, pectinase, $\alpha$-amylase, and laccase) $[170,171]$. The same group [170] tested the electrochemical behavior of GOx and $\beta$-galactosidase functionalized PNFs from crystallin proteins using the same gold electrodes platform. The electrochemistry results indicated that the enzymes deposited on the PNFs retained their activity.

\section{Conclusions and forecast}

Already in 2008, the potential use of PNF composites in the manufacturing of largescale products was highlighted as Nokia and the University of Cambridge developed a concept device of a partially biodegradable stretchable and bendable mobile phone containing amyloid-like nanofibrils [172]. Since then, the number of published articles demonstrating the potential of using PNFs in various nanocomposites is increasing. However, very few of the presented concepts are fully ready for industrial use, and, to our knowledge, there is no commercial product based on this type of material today. Yet, it is possible to envision of potential industrial applications of these types of nanocomposites. 
An evident application of PNFs is to reinforce/stiffen a mechanically poorer material matrix. If a system can be developed where, during mechanical deformation, significant fibril disentanglement occurs, a nanomaterial with improved toughness can be obtained. The low weight and the biocompatibility of the PNFs make them an interesting option, where today nonbiobased, less biocompatible "fibers" are used. The small fibril cross sections render them, however, less effective as a reinforcement than, for example, glass and carbon fibers. One option is then to create "bundles" of fibrils and to mix these into the polymer matrix. If these are oriented uniaxially or biaxially during the nanocomposite production, a nanocomposite with different mechanical features will be at hand. Important for optimal mechanical properties are a high aspect fibril geometry and good cohesion between the fibrils and the matrix. The former can be obtained by proper choice of fibril material and fibril formation conditions and the latter can be obtained by the use of a coupling agent, a compatibilizer, or a surface treatment of the fibrils. If the matrix and fibrils are of the same origin, good blend miscibility and compatibility are favored. In addition, the fibril contour shape may have an impact on the nanocomposite mechanical properties, and this may be tailored by a proper choice of fibril formation conditions.

The possibility to control the nanostructure of protein components could lead to a renaissance for protein-based materials. Engineered protein materials were indeed explored during the early 20th century but they have been out of the spotlight since the invention of fully synthetic plastics. The recent focus on more sustainable materials has renewed the interest for biopolymers although their performances are still not at the level of the bulk synthetic polymers. Through the control of the protein nanostructure, we could take one step closer to producing artificial mimics of the high-performance protein materials in nature, such as silks or wool.

Nanocomposites with a network of functionalized PNFs will likely show unique features. With nanofibrils decorated with conductive metal atoms, it should be possible to obtain a nanocomposite with conductive percolation at very low fibril contents. Unique features may also arise by functionalizing the fibrils with magnetic particles, chromophores, or thermally conductive species. If the fibrils can be oriented during the production of the nanocomposite, these properties can also be designed to be nonisotropic.

A nanocomposite with an organic or inorganic matrix and PNFs should be possible to use as a template for a nanoporous materials. With selective dissolution of the PNFs, a nanoporous network will develop inside the polymer matrix, leading to a porous material probably showing unique capillary suction and absorption when exposed to liquids. It is likely that this material would also have unique gas selective and membrane properties.

The small dimensions of the fibrils lead to a fibril network that can be very rapidly dissolved in a solvent. This feature may be used to improve the rate of dissolution of a polymer matrix (dissolvable in the same solvent). The same thing may occur also with respect to biodegradation kinetics. 
To transform the various material concepts from the lab scale to industrial production, improved knowledge about potential raw materials for PNFs is required. Up to date, much of the proof-of-principle work up to date has been done with $\beta$ lactoglobulin from whey. It is indeed a very useful model system that can easily be obtained with high purity. However, such high purity might not be necessary in all applications. Similar PNFs can be produced from crude whey protein concentrate or whey protein isolate. PNF composites could indeed become really attractive if the nanofibrils can be produced from true industrial waste products, such as crystalline proteins from fish waste as demonstrated by Healy et al. [23] Whey is a largescale by-product from cheese manufacturing but it has several other areas of use today. Many of the plant proteins for which PNF formation has been reported have a value in the food industry, which is often the reason why the fibrillation have been studied. Potentially, the food industry could be the ones that take the lead in the use of PNFs in larger scale. Demonstration of PNF formation from nonfood plants could open up for new crops with material production as the main purpose.

\section{Acknowledgment}

Financial support from the China Scholarship Council and Swedish Research Council Formas is gratefully acknowledged.

\section{References}

[1] A.K.-T. Lau, D. Hui, The revolutionary creation of new advanced materials—carbon nanotube composites, Compos. Part B: Eng. 33 (4) (2002) 263-277.

[2] H.P.S. Abdul Khalil, A.H. Bhat, A.F. Ireana Yusra, Green composites from sustainable cellulose nanofibrils: a review, Carbohydr. Polym. 87 (2) (2012) 963-979.

[3] F. Chiti, C.M. Dobson, Protein misfolding, functional amyloid, and human disease, Annu. Rev. Biochem. 75 (2006) 333-366.

[4] T.P.J. Knowles, M.J. Buehler, Nanomechanics of functional and pathological amyloid materials, Nat. Nanotechnol. 6 (8) (2011) 469-479.

[5] M. Lasse, D. Ulluwishewa, J. Healy, D. Thompson, A. Miller, N. Roy, et al., Evaluation of protease resistance and toxicity of amyloid-like food fibrils from whey, soy, kidney bean, and egg white, Food Chem. 192 (2016) 491-498.

[6] T.P. Knowles, R. Mezzenga, Amyloid fibrils as building blocks for natural and artificial functional materials, Adv. Mater. 28 (31) (2016) 6546-6561.

[7] J.D. Sipe, M.D. Benson, J.N. Buxbaum, S.-i. Ikeda, G. Merlini, M.J.M. Saraiva, et al., Amyloid fibril proteins and amyloidosis: chemical identification and clinical classification, Amyloid 23 (4) (2016) 209-213.

[8] M.S. Dueholm, S.V. Petersen, M. Sonderkaer, P. Larsen, G. Christiansen, K.L. Hein, et al., Functional amyloid in Pseudomonas, Mol. Microbiol. 77 (4) (2010) 1009-1020.

[9] J.R. Glover, A.S. Kowal, E.C. Schirmer, M.M. Patino, J.J. Liu, S. Lindquist, Selfseeded fibers formed by Sup35, the protein determinant of [PSI+], a heritable prion-like factor of S. cerevisiae, Cell 89 (1997) 811-819. 
[10] K.L. Taylor, N. Cheng, R.W. Williams, A.C. Steven, R.B. Wickner, Prion domain initiation of amyloid formation in vitro from native Ure2p, Science 283 (5406) (1999) 1339-1343.

[11] S. Dos Reis, B. Coulary-Salin, V. Forge, I. Lascu, J. Begueret, S.J. Saupe, The HET-s prion protein of the filamentous fungus Podospora anserina aggregates in vitro into amyloid-like fibrils, J. Biol. Chem. 277 (8) (2002) 5703-5706.

[12] D.E. Barlow, G.H. Dickinson, B. Orihuela, J.L. Kulp, D. Rittschof, K.J. Wahl, Characterization of the adhesive plaque of the barnacle Balanus amphitrite: amyloid-like nanofibrils are a major component, Langmuir 26 (9) (2010) 6549-6556.

[13] M. Nakano, K. Kamino, Amyloid-like conformation and interaction for the selfassembly in barnacle underwater cement, Biochemistry 54 (3) (2015) 826-835.

[14] V.A. Iconomidou, G. Vriend, S.J. Hamodrakas, Amyloids protect the silkmoth oocyte and embryo, FEBS Lett. 479 (3) (2000) 141-145.

[15] D.M. Fowler, A.V. Koulov, C. Alory-Jost, M.S. Marks, W.E. Balch, J.W. Kelly, Functional amyloid formation within mammalian tissue, PLoS Biol. 4 (1) (2006) 100-107.

[16] J. Goers, S.E. Permyakov, E.A. Permyakov, V.N. Uversky, A.L. Fink, Conformational prerequisites for $\alpha$-lactalbumin fibrillation, Biochemistry 41 (41) (2002) 12546-12551.

[17] D. Otzen, Functional amyloid: turning swords into plowshares, Prion 4 (4) (2010) 256-264.

[18] S.M. Loveday, S.G. Anema, H. Singh, $\beta$-Lactoglobulin nanofibrils: the long and the short of it, Int. Dairy J. 67 (2017) 35-45.

[19] N. Jayawardena, M. Kaur, S. Nair, J. Malmstrom, D. Goldstone, L. Negron, et al., Amyloid fibrils from hemoglobin, Biomolecules 7 (2) (2017).

[20] N.K. Holm, S.K. Jespersen, L.V. Thomassen, T.Y. Wolff, P. Sehgal, L.A. Thomsen, et al., Aggregation and fibrillation of bovine serum albumin, BBA Proteins Proteom. 1774 (9) (2007) 1128-1138.

[21] D. Saiz-Sanchez, A. Flores-Cuadrado, I. Ubeda-Bañon, C. de la Rosa-Prieto, A. Martinez-Marcos, Interneurons in the human olfactory system in Alzheimer's disease, Exp. Neurol. 276 (2016) 13-21.

[22] F.G. Pearce, S.H. Mackintosh, J.A. Gerrard, Formation of amyloid-like fibrils by ovalbumin and related proteins under conditions relevant to food processing, J. Agric. Food Chem. 55 (2) (2007) 318-322.

[23] J. Healy, K. Wong, E.B. Sawyer, C. Roux, L. Domigan, S.L. Gras, et al., Polymorphism and higher order structures of protein nanofibers from crude mixtures of fish lens crystallins: toward useful materials, Biopolymers 97 (8) (2012) 595-606.

[24] C.H. Tang, C.S. Wang, Formation and characterization of amyloid-like fibrils from soy $\beta$-conglycinin and glycinin, J. Agric. Food Chem. 58 (20) (2010) 11058-11066.

[25] M.R. Krebs, D.K. Wilkins, E.W. Chung, M.C. Pitkeathly, A.K. Chamberlain, J. Zurdo, et al., Formation and seeding of amyloid fibrils from wild-type hen lysozyme and a peptide fragment from the $\beta$-domain, J. Mol. Biol. 300 (3) (2000) 541-549.

[26] C. Akkermans, A.J. Van der Goot, P. Venema, H. Gruppen, J.M. Vereijken, E. Van der Linden, et al., Micrometer-sized fibrillar protein aggregates from soy glycinin and soy protein isolate, J. Agric. Food Chem. 55 (24) (2007) 9877-9882.

[27] V. Vetri, C. Canale, A. Relini, F. Librizzi, V. Militello, A. Gliozzi, et al., Amyloid fibrils formation and amorphous aggregation in concanavalin A, Biophys. Chem. 125 (1) (2007) 184-190. 
[28] C.-H. Tang, Y.-H. Zhang, Q.-B. Wen, Q. Huang, Formation of amyloid fibrils from kidney bean 7S globulin (phaseolin) at pH 2.0, J. Agric. Food Chem. 58 (2010) 8061-8068.

[29] D.M. Ridgley, K.C. Ebanks, J.R. Barone, Peptide mixtures can self-assemble into large amyloid fibers of varying size and morphology, Biomacromolecules 12 (2011) 3770-3779.

[30] S.H. Mackintosh, S.J. Meade, J.P. Healy, K.H. Sutton, N.G. Larsen, A.M. Squires, et al., Wheat glutenin proteins assemble into a nanostructure with unusual structural features, J. Cereal Sci. 49 (1) (2009) 157-162.

[31] J. Liu, C.H. Tang, Heat-induced fibril assembly of vicilin at $\mathrm{pH}$ 2.0: reaction kinetics, influence of ionic strength and protein concentration, and molecular mechanism, Food Res. Int. 51 (2) (2013) 621-632.

[32] S.A. Bhat, B. Bano, Conformational behaviour and aggregation of chickpea cystatin in trifluoroethanol: effects of epicatechin and tannic acid, Arch. Biochem. Biophys. 562 (2014) 51-61.

[33] J.Z. Zhou, H. Zhang, H.Y. Yang, L. Wang, H.F. Qian, Formation of heat-induced cottonseed congossypin(7S) fibrils at pH 2.0, J. Sci. Food Agric. 94 (10) (2014) 2009-2015.

[34] C.D. Munialo, A.H. Martin, E. van der Linden, H.H.J. de Jongh, Fibril formation from pea protein and subsequent gel formation, J. Agric. Food Chem. 62 (11) (2014) 2418-2427.

[35] M. Yolamanova, C. Meier, A.K. Shaytan, V. Vas, C.W. Bertoncini, F. Arnold, et al., Peptide nanofibrils boost retroviral gene transfer and provide a rapid means for concentrating viruses, Nat. Nanotechnol. 8 (2013) 130-136.

[36] L.H. Huang, Y.H. Zhang, H.B. Li, Self-assembly of rice bran globulin fibrils in electrostatic screening: nanostructure and gels, J. Nanomater. (2014).

[37] D. Santi Swarupini, A.K. Bhuyan, Amyloid fibrillation of an intrinsically disordered plant phloem protein AtPP16-1 under acidic condition, Biophys. Chem. 237 (2018) 1-8.

[38] J.I. Guijarro, M. Sunde, J.A. Jones, I.D. Campbell, C.M. Dobson, Amyloid fibril formation by an SH3 domain, Proc. Natl. Acad. Sci. U. S. A. 95 (8) (1998) 4224-4228.

[39] F. Chiti, P. Webster, N. Taddei, A. Clark, M. Stefani, G. Ramponi, et al., Designing conditions for in vitro formation of amyloid protofilaments and fibrils, Proc. Natl. Acad. Sci. U. S. A. 96 (7) (1999) 3590-3594.

[40] M. Kaur, J. Healy, M. Vasudevamurthy, M. Lasse, L. Puskar, M.J. Tobin, et al., Stability and cytotoxicity of crystallin amyloid nanofibrils, Nanoscale 6(21) (2014) 13169-13178.

[41] T. Härd, C. Lendel, Inhibition of amyloid formation, J. Mol. Biol. 421 (4-5) (2012) $441-465$.

[42] G. Bhak, S. Lee, J.W. Park, S. Cho, S.R. Paik, Amyloid hydrogel derived from curly protein fibrils of $\alpha$-synuclein, Biomaterials 31 (23) (2010) 5986-5995.

[43] S.L. Gras, A.K. Tickler, A.M. Squires, G.L. Devlin, M.A. Horton, C.M. Dobson, et al., Functionalised amyloid fibrils for roles in cell adhesion, Biomaterials 29 (11) (2008) 1553-1562.

[44] Y. Liang, P. Guo, S.V. Pingali, S. Pabit, P. Thiyagarajan, K.M. Berland, et al., Light harvesting antenna on an amyloid scaffold, Chem. Commun. (48) (2008) 6522-6524.

[45] C. Zhong, T. Gurry, A.A. Cheng, J. Downey, Z. Deng, C.M. Stultz, et al., Strong underwater adhesives made by self-assembling multi-protein nanofibres, Nat. Nanotechnol. 9 (10) (2014) 858-866.

[46] D. Men, Y.C. Guo, Z.P. Zhang, H.P. Wei, Y.F. Zhou, Z.Q. Cui, et al., Seeding-induced self-assembling protein nanowires dramatically increase the sensitivity of immunoassays, Nano Lett. 9 (6) (2009) 2246-2250. 
[47] K. Pan, Q.X. Zhong, Amyloid-like fibrils formed from intrinsically disordered caseins: physicochemical and nanomechanical properties, Soft Matter 11 (29) (2015) 5898-5904.

[48] G. Wei, Z. Su, N.P. Reynolds, P. Arosio, I.W. Hamley, E. Gazit, et al., Self-assembling peptide and protein amyloids: from structure to tailored function in nanotechnology, Chem. Soc. Rev. 46 (15) (2017) 4661-4708.

[49] L.C. Serpell, Alzheimer's amyloid fibrils: structure and assembly, BBA: Mol. Basis Dis. 1502 (1) (2000) 16-30.

[50] M. Sunde, L.C. Serpell, M. Bartlam, P.E. Fraser, M.B. Pepys, C.C.F. Blake, Common core structure of amyloid fibrils by synchrotron X-ray diffraction, J. Mol. Biol. 273 (3) (1997) 729-739.

[51] M.R. Sawaya, S. Sambashivan, R. Nelson, M.I. Ivanova, S.A. Sievers, M.I. Apostol, et al., Atomic structures of amyloid cross- $\beta$ spines reveal varied steric zippers, Nature 447 (2007) 453-457.

[52] R. Nelson, M.R. Sawaya, M. Balbirnie, A.Ø. Madsen, C. Riekel, R. Grothe, et al., Structure of the cross- $\beta$ spine of amyloid-like fibrils, Nature 435 (2005) 773-778.

[53] M. Balbirnie, R. Grothe, D.S. Eisenberg, An amyloid-forming peptide from the yeast prion Sup35 reveals a dehydrated $\beta$-sheet structure for amyloid, Proc. Natl. Acad. Sci. U. S. A. 98 (5) (2001) 2375-2380.

[54] J.R. Lewandowski, P.C.A. van der Wel, M. Rigney, N. Grigorieff, R.G. Griffin, Structural complexity of a composite amyloid fibril, J. Am. Chem. Soc. 133 (37) (2011) 14686-14698.

[55] M. Fändrich, J. Meinhardt, N. Grigorieff, Structural polymorphism of Alzheimer A $\beta$ and other amyloid fibrils, Prion 3 (2) (2009) 89-93.

[56] T.P. Knowles, A.W. Fitzpatrick, S. Meehan, H.R. Mott, M. Vendruscolo, C.M. Dobson, et al., Role of intermolecular forces in defining material properties of protein nanofibrils, Science 318 (5858) (2007) 1900-1903.

[57] A. Kamada, N. Mittal, L.D. Söderberg, T. Ingverud, W. Ohm, S.V. Roth, et al., Flowassisted assembly of nanostructured protein microfibers, Proc. Natl. Acad. Sci. U. S. A. 114 (6) (2017) 1232-1237.

[58] D. Hamada, C.M. Dobson, A kinetic study of $\beta$-lactoglobulin amyloid fibril formation promoted by urea, Protein Sci. 11 (10) (2002) 2417-2426.

[59] W.S. Gosal, A.H. Clark, P.D.A. Pudney, S.B. Ross-Murphy, Novel amyloid fibrillar networks derived from a globular protein: $\beta$-lactoglobulin, Langmuir 18 (19) (2002) 7174-7181.

[60] G.M. Kavanagh, A.H. Clark, S.B. Ross-Murphy, Heat-induced gelation of globular proteins: part 3. Molecular studies on low pH $\beta$-lactoglobulin gels, Int. J. Biol. Macromol. 28 (1) (2000) 41-50.

[61] C. Veerman, H. Ruis, L.M.C. Sagis, E. van der Linden, Effect of electrostatic interactions on the percolation concentration of fibrillar $\beta$-lactoglobulin gels, Biomacromolecules 3 (4) (2002) 869-873.

[62] A. Kroes-Nijboer, P. Venema, J. Bouman, E. van der Linden, Influence of protein hydrolysis on the growth kinetics of $\beta$-Iacotoglobulin fibrils, Langmuir 27 (10) (2011) 5753-5761.

[63] C. Akkermans, P. Venema, A.J. van der Goot, H. Gruppen, E.J. Bakx, R.M. Boom, et al., Peptides are building blocks of heat-induced fibrillar protein aggregates of $\beta$ lactoglobulin formed at pH 2, Biomacromolecules 9 (5) (2008) 1474-1479. 
[64] C. Lara, S. Gourdin-Bertin, J. Adamcik, S. Bolisetty, R. Mezzenga, Self-assembly of ovalbumin into amyloid and non-amyloid fibrils, Biomacromolecules 13 (12) (2012) 4213-4221.

[65] X. Ye, M.S. Hedenqvist, M. Langton, C. Lendel, On the role of peptide hydrolysis for fibrillation kinetics and amyloid fibril morphology, RSC Adv. (13) (2018) 6915-6924.

[66] S.E. Bondos, Methods for measuring protein aggregation, Curr. Anal. Chem. 2 (2) (2006) 157-170.

[67] A.M. Morris, M.A. Watzky, R.G. Finke, Protein aggregation kinetics, mechanism, and curve-fitting: a review of the literature, BBA Proteins Proteom. 1794 (3) (2009) 375-397.

[68] G. Meisl, J.B. Kirkegaard, P. Arosio, T.C. Michaels, M. Vendruscolo, C.M. Dobson, et al., Molecular mechanisms of protein aggregation from global fitting of kinetic models, Nat. Protoc. 11 (2) (2016) 252-272.

[69] F. Ferrone, Analysis of protein aggregation kinetics, Methods Enzymol. 309 (1999) 256-274. Academic Press.

[70] T.P.J. Knowles, C.A. Waudby, G.L. Devlin, S.I.A. Cohen, A. Aguzzi, M. Vendruscolo, et al., An analytical solution to the kinetics of breakable filament assembly, Science 326 (5959) (2009) 1533-1537.

[71] M. Kasai, S. Asakura, F. Oosawa, The cooperative nature of G-F transformation of actin, Biochim. Biophys. Acta 57 (1) (1962) 22-31.

[72] J. Hofrichter, P.D. Ross, W.A. Eaton, Kinetics and mechanism of deoxyhemoglobin S gelation: a new approach to understanding sickle cell disease, Proc. Natl. Acad. Sci. U. S. A. 71 (12) (1974) 4864-4868.

[73] V.K.L. Mer, Nucleation in phase transitions, Ind. Eng. Chem. Res. 44 (6) (1952) $1270-1277$.

[74] A. Wegner, J. Engel, Kinetics of the cooperative association of actin to actin filament, Biophys. Chem. 3 (3) (1975) 215-225.

[75] F. Oosawa, M. Kasai, A theory of linear and helical aggregations of macromolecules, J. Mol. Biol. 4 (1) (1962) 10-21.

[76] F.A. Ferrone, J. Hofrichter, H.R. Sunshine, W.A. Eaton, Kinetic-studies on photolysisinduced gelation of sickle-cell hemoglobin suggest a new mechanism, Biophys. J. 32 (1) (1980) 361-380.

[77] A. Wegner, P. Savko, Fragmentation of actin-filaments, Biochemistry 21 (8) (1982) 1909-1913.

[78] M.F. Bishop, F.A. Ferrone, Kinetics of nucleation-controlled polymerization - a perturbation treatment for use with a secondary pathway, Biophys. J. 46 (5) (1984) 631-644.

[79] F. Oosawa, S. Asakura, Thermodynamics of the Polymerization of Protein, Academic Press, London/New York, 1975.

[80] S. Perrett, G.W. Jones, Insights into the mechanism of prion propagation, Curr. Opin. Struct. Biol. 18 (1) (2008) 52-59.

[81] I.V. Baskakov, Branched chain mechanism of polymerization and ultrastructure of prion protein amyloid fibrils, FEBS J. 274 (15) (2007) 3756-3765.

[82] S.I.A. Cohen, S. Linse, L.M. Luheshi, E. Hellstrand, D.A. White, L. Rajah, et al., Proliferation of amyloid- $\beta 42$ aggregates occurs through a secondary nucleation mechanism, Proc. Natl. Acad. Sci. U. S. A. 110 (24) (2013) 9758-9763.

[83] G. Meis1, X. Yang, E. Hellstrand, B. Frohm, J.B. Kirkegaard, S.I. Cohen, et al., Differences in nucleation behavior underlie the contrasting aggregation kinetics of the A $\beta 40$ and A 342 peptides, Proc. Natl. Acad. Sci. U. S. A. 111 (26) (2014) 9384-9389. 
[84] T.R. Serio, A.G. Cashikar, A.S. Kowal, G.J. Sawicki, J.J. Moslehi, L. Serpell, et al., Nucleated conformational conversion and the replication of conformational information by a prion determinant, Science 289 (5483) (2000) 1317-1321.

[85] H. Naiki, N. Hashimoto, S. Suzuki, H. Kimura, K. Nakakuki, F. Gejyo, Establishment of a kinetic model of dialysis-related amyloid fibril extension in vitro, Amyloid 4 (4) (1997) 223-232.

[86] F. Chiti, N. Taddei, F. Baroni, C. Capanni, M. Stefani, G. Ramponi, et al., Kinetic partitioning of protein folding and aggregation, Nat. Struct. Biol. 9 (2002) 137-143.

[87] S.M. Loveday, X.L. Wang, M.A. Rao, S.G. Anema, L.K. Creamer, H. Singh, Tuning the properties of $\beta$-lactoglobulin nanofibrils with $\mathrm{pH}, \mathrm{NaCl}$ and $\mathrm{CaCl}_{2}$, Int. Dairy J. 20 (9) (2010) 571-579.

[88] S. Bolisetty, J.J. Vallooran, J. Adamcik, R. Mezzenga, Magnetic-responsive hybrids of $\mathrm{Fe}_{3} \mathrm{O}_{4}$ nanoparticles with $\beta$-lactoglobulin amyloid fibrils and nanoclusters, ACS Nano 7 (7) (2013) 6146-6155.

[89] S. Laurent, D. Forge, M. Port, A. Roch, C. Robic, L. Vander Elst, et al., Magnetic iron oxide nanoparticles: synthesis, stabilization, vectorization, physicochemical characterizations, and biological applications, Chem. Rev. 108 (6) (2008) 2064-2110.

[90] M. Mahmoudi, I. Lynch, M.R. Ejtehadi, M.P. Monopoli, F.B. Bombelli, S. Laurent, Protein-nanoparticle interactions: opportunities and challenges, Chem. Rev. 111 (9) (2011) 5610-5637.

[91] S. Linse, C. Cabaleiro-Lago, W.-F. Xue, I. Lynch, S. Lindman, E. Thulin, et al., Nucleation of protein fibrillation by nanoparticles, Proc. Natl. Acad. Sci. U. S. A. 104 (21) (2007) 8691-8696.

[92] J.F. Smith, T.P.J. Knowles, C.M. Dobson, C.E. MacPhee, M.E. Welland, Characterization of the nanoscale properties of individual amyloid fibrils, Proc. Natl. Acad. Sci. U. S. A. 103 (43) (2006) 15806-15811.

[93] I. Usov, R. Mezzenga, Correlation between nanomechanics and polymorphic conformations in amyloid fibrils, ACS Nano 8 (11) (2014) 11035-11041.

[94] F.T. Chan, G.S. Kaminski Schierle, J.R. Kumita, C.W. Bertoncini, C.M. Dobson, C. F. Kaminski, Protein amyloids develop an intrinsic fluorescence signature during aggregation, Analyst 138 (7) (2013) 2156-2162.

[95] R. Khurana, V.N. Uversky, L. Nielsen, A.L. Fink, Is Congo red an amyloid-specific dye? J. Biol. Chem. 276 (25) (2001) 22715-22721.

[96] N. Amdursky, Y. Erez, D. Huppert, Molecular rotors: what lies behind the high sensitivity of the thioflavin-T fluorescent marker, Acc. Chem. Res. 45 (9) (2012) 1548-1557.

[97] D. Sjölander, J. Bijzet, B.P. Hazenberg, K.P.R. Nilsson, P. Hammarström, Sensitive and rapid assessment of amyloid by oligothiophene fluorescence in subcutaneous fat tissue, Amyloid 22 (1) (2015) 19-25.

[98] T. Klingstedt, K. Nilsson, R. Peter, Luminescent conjugated poly- and oligothiophenes: optical ligands for spectral assignment of a plethora of protein aggregates, Biochem. Soc. Trans. 40 (4) (2012) 704-710.

[99] R. Mishra, D. Sjölander, P. Hammarström, Spectroscopic characterization of diverse amyloid fibrils in vitro by the fluorescent dye Nile red, Mol. BioSyst. 7 (4) (2011) 1232-1240.

[100] T.P.J. Knowles, T.W. Oppenheim, A.K. Buell, D.Y. Chirgadze, M.E. Welland, Nanostructured films from hierarchical self-assembly of amyloidogenic proteins, Nat. Nanotechnol. 5 (3) (2010) 204-207. 
[101] A. Kroes-Nijboer, P. Venema, E. van der Linden, Fibrillar structures in food, Food Funct. 3 (3) (2012) 221-227.

[102] A.M. Jonker, D.W.P.M. Lowik, J.C.M. van Hest, Peptide- and protein-based hydrogels, Chem. Mater. 24 (5) (2012) 759-773.

[103] S.M. Loveday, J. Su, M.A. Rao, S.G. Anema, H. Singh, Effect of calcium on the morphology and functionality of whey protein nanofibrils, Biomacromolecules 12 (10) (2011) 3780-3788.

[104] S.M. Loveday, J. Su, M.A. Rao, S.G. Anema, H. Singh, Whey protein nanofibrils: kinetic, rheological and morphological effects of group IA and IIA cations, Int. Dairy J. 26 (2) (2012) 133-140.

[105] C. Akkermans, A.J. van der Goot, P. Venema, E. van der Linden, R.M. Boom, Formation of fibrillar whey protein aggregates: influence of heat and shear treatment, and resulting rheology, Food Hydrocoll. 22 (7) (2008) 1315-1325.

[106] C. Veerman, H. Baptist, L.M.C. Sagis, E. van der Linden, A new multistep Ca ${ }^{2+}$ induced cold gelation process for $\beta$-lactoglobulin, J. Agric. Food Chem. 51 (13) (2003) 3880-3885.

[107] S. Sadeghi, A. Madadlou, M. Yarmand, Microemulsification-cold gelation of whey proteins for nanoencapsulation of date palm pit extract, Food Hydrocoll. 35 (2014) 590-596.

[108] C. Veerman, L.M.C. Sagis, J. Heck, E. van der Linden, Mesostructure of fibrillar bovine serum albumin gels, Int. J. Biol. Macromol. 31 (4) (2003) 139-146.

[109] S.M. Loveday, X.L. Wang, M.A. Rao, S.G. Anema, H. Singh, Effect of pH, NaCl, $\mathrm{CaCl}_{2}$ and temperature on self-assembly of $\beta$-lactoglobulin into nanofibrils: a central composite design study, J. Agric. Food Chem. 59 (15) (2011) 8467-8474.

[110] M. Mohammadian, A. Madadlou, Cold-set hydrogels made of whey protein nanofibrils with different divalent cations, Int. J. Biol. Macromol. 89 (2016) 499-506.

[111] E. Sedlák, L. Stagg, P. Wittung-Stafshede, Effect of Hofmeister ions on protein thermal stability: roles of ion hydration and peptide groups? Arch. Biochem. Biophys. 479 (1) (2008) 69-73.

[112] T. Farjami, A. Madadlou, M. Labbafi, Modulating the textural characteristics of whey protein nanofibril gels with different concentrations of calcium chloride, J. Dairy Res. 83 (1) (2016) 109-114.

[113] A.M. Corrigan, C. Müller, M.R.H. Krebs, The formation of nematic liquid crystal phases by hen lysozyme amyloid fibrils, J. Am. Chem. Soc. 128 (46) (2006) 14740-14741.

[114] R.H. Baughman, A.A. Zakhidov, W.A. de Heer, Carbon nanotubes-the route toward applications, Science 297 (5582) (2002) 787-792.

[115] F.G. Bäcklund, J. Pallbo, N. Solin, Controlling amyloid fibril formation by partial stirring, Biopolymers 105 (5) (2016) 249-259.

[116] N.M.D. Courchesne, A. Duraj-Thatte, P.K.R. Tay, P.Q. Nguyen, N.S. Joshi, Scalable production of genetically engineered nanofibrous macroscopic materials via filtration, ACS Biomater. Sci. Eng. 3 (5) (2017) 733-741.

[117] Z. Feng, G. Wu, C. Liu, D. Li, B. Jiang, X. Zhang, Edible coating based on whey protein isolate nanofibrils for antioxidation and inhibition of product browning, Food Hydrocoll. 79 (2018) 179-188.

[118] K.M. Håkansson, A.B. Fall, F. Lundell, S. Yu, C. Krywka, S.V. Roth, et al., Hydrodynamic alignment and assembly of nanofibrils resulting in strong cellulose filaments, Nat. Commun. 5 (2014) 4018.

[119] C. Meier, M.E. Welland, Wet-spinning of amyloid protein nanofibers into multifunctional high-performance biofibers, Biomacromolecules 12 (10) (2011) 3453-3459. 
[120] P.Q. Nguyen, Z. Botyanszki, P.K.R. Tay, N.S. Joshi, Programmable biofilm-based materials from engineered curli nanofibres, Nat. Commun. 5 (2014) 4945.

[121] M.M.J. Treacy, T.W. Ebbesen, J.M. Gibson, Exceptionally high Young's modulus observed for individual carbon nanotubes, Nature 381 (1996) 678-680.

[122] T. Oppenheim, T.P. Knowles, S.P. Lacour, M.E. Welland, Fabrication and characterisation of protein fibril-elastomer composites, Acta Biomater. 6 (4) (2010) 1337-1341.

[123] S.P. Rao, S.J. Meade, J.P. Healy, K.H. Sutton, N.G. Larsen, M.P. Staiger, et al., Amyloid fibrils as functionalizable components of nanocomposite materials, Biotechnol. Prog. 28 (1) (2011) 248-256.

[124] N. Byrne, N. Hameed, O. Werzer, Q. Guo, The preparation of novel nanofilled polymer composites using poly(l-lactic acid) and protein fibers, Eur. Polym. J. 47 (6) (2011) $1279-1283$.

[125] X. Ye, K. Junel, M. Gällstedt, M. Langton, X. Wei, C. Lendel, et al., An all-protein nanocomposite based on whey protein nanofibrils in a whey protein matrix, ACS Sustain. Chem. Eng. 6 (2018) 5462-5469.

[126] E.C. Claunch, D.M. Ridgley, J.R. Barone, Completely self-assembled fiber composites, Compos. Sci. Technol. 117 (2015) 1-8.

[127] A.W. Jensen, S.R. Wilson, D.I. Schuster, Biological applications of fullerenes, Bioorg. Med. Chem. 4 (6) (1996) 767-779.

[128] P. Avouris, M. Freitag, V. Perebeinos, Carbon-nanotube photonics and optoelectronics, Nat. Photonics 2 (2008) 341-350.

[129] C. Li, R. Mezzenga, The interplay between carbon nanomaterials and amyloid fibrils in bio-nanotechnology, Nanoscale 5 (14) (2013) 6207-6218.

[130] C.L. Li, J. Adamcik, R. Mezzenga, Biodegradable nanocomposites of amyloid fibrils and graphene with shape-memory and enzyme-sensing properties, Nat. Nanotechnol. 7 (2012) 421-427.

[131] C.X. Li, A.K. Born, T. Schweizer, M. Zenobi-Wong, M. Cerruti, R. Mezzenga, Amyloid-hydroxyapatite bone biomimetic composites, Adv. Mater. 26 (20) (2014) 3207-3212.

[132] C. Li, R. Mezzenga, Functionalization of multiwalled carbon nanotubes and their pH-responsive hydrogels with amyloid fibrils, Langmuir 28 (27) (2012) 10142-10146.

[133] J.-M. Jung, G. Savin, M. Pouzot, C. Schmitt, R. Mezzenga, Structure of heat-induced $\beta-$ Lactoglobulin aggregates and their complexes with sodium-dodecyl sulfate, Biomacromolecules 9 (9) (2008) 2477-2486.

[134] S. Bolisetty, R. Mezzenga, Amyloid-carbon hybrid membranes for universal water purification, Nat. Nanotechnol. 11 (4) (2016) 365-371.

[135] S. Bolisetty, N. Reinhold, C. Zeder, M.N. Orozco, R. Mezzenga, Efficient purification of arsenic-contaminated water using amyloid-carbon hybrid membranes, Chem. Commun. 53 (42) (2017) 5714-5717.

[136] S. Bolisetty, M. Arcari, J. Adamcik, R. Mezzenga, Hybrid amyloid membranes for continuous flow catalysis, Langmuir 31 (51) (2015) 13867-13873.

[137] S. Bolisetty, C.S. Boddupalli, S. Handschin, K. Chaitanya, J. Adamcik, Y. Saito, et al., Amyloid fibrils enhance transport of metal nanoparticles in living cells and induced cytotoxicity, Biomacromolecules 15 (7) (2014) 2793-2799.

[138] S. Bolisetty, J.J. Vallooran, J. Adamcik, S. Handschin, F. Gramm, R. Mezzenga, Amyloid-mediated synthesis of giant, fluorescent, gold single crystals and their hybrid sandwiched composites driven by liquid crystalline interactions, J. Colloid Interface Sci. 361 (1) (2011) 90-96. 
[139] C. Lara, S. Handschin, R. Mezzenga, Towards lysozyme nanotube and 3D hybrid selfassembly, Nanoscale 5 (16) (2013) 7197-7201.

[140] J. Jiu, K. Suganuma, M. Nogi, Effect of additives on the morphology of single-crystal $\mathrm{Au}$ nanosheet synthesized using the polyol process, J. Mater. Sci. 46 (14) (2011) 4964-4970.

[141] Z. Li, Z. Liu, J. Zhang, B. Han, J. Du, Y. Gao, et al., Synthesis of single-crystal gold nanosheets of large size in ionic lquids, J. Phys. Chem. B 109 (30) (2005) 14445-14448.

[142] H.L. Qin, D. Wang, Z.L. Huang, D.M. Wu, Z.C. Zeng, B. Ren, et al., Thicknesscontrolled synthesis of ultrathin Au sheets and surface plasmonic property, J. Am. Chem. Soc. 135 (34) (2013) 12544-12547.

[143] J.Y.Zhou, A. Saha, J. Adamcik, H.Q. Hu, Q.S. Kong, C.X. Li, et al., Macroscopic singlecrystal gold microflakes and their devices, Adv. Mater. 27 (11) (2015) 1945-1950.

[144] C.X. Li, S. Bolisetty, R. Mezzenga, Hybrid nanocomposites of gold single-crystal platelets and amyloid fibrils with tunable fluorescence, conductivity, and sensing properties, Adv. Mater. 25 (27) (2013) 3694-3700.

[145] M. Reches, E. Gazit, Casting metal nanowires within discrete self-assembled peptide nanotubes, Science 300 (5619) (2003) 625-627.

[146] M. Malisauskas, R. Meskys, L.A. Morozova-Roche, Ultrathin silver nanowires produced by amyloid biotemplating, Biotechnol. Prog. 24 (5) (2008) 1166-1170.

[147] J. Zhao, S. Bolisetty, S. Isabettini, J. Kohlbrecher, J. Adamcik, P. Fischer, et al., Continuous paranematic ordering of rigid and semiflexible amyloid- $\mathrm{Fe}_{3} \mathrm{O}_{4}$ hybrid fibrils in an external magnetic field, Biomacromolecules 17 (8) (2016) 2555-2561.

[148] Y. Shen, G. Nystrom, R. Mezzenga, Amyloid fibrils form hybrid colloidal gels and aerogels with dispersed $\mathrm{CaCO}_{3}$ nanoparticles, Adv. Funct. Mater. 27 (45) (2017)1700897.

[149] A. Herland, P. Björk, K.P.R. Nilsson, J.D.M. Olsson, P. Åsberg, P. Konradsson, et al., Electroactive luminescent self-assembled bio-organic nanowires: integration of semiconducting oligoelectrolytes within amyloidogenic proteins, Adv. Mater. 17 (14) (2005) 1466-1471.

[150] M. Hamedi, A. Herland, R.H. Karlsson, O. Inganäs, Electrochemical devices made from conducting nanowire networks self-assembled from amyloid fibrils and alkoxysulfonate PEDOT, Nano Lett. 8 (6) (2008) 1736-1740.

[151] N. Solin, O. Inganäs, Protein nanofibrils balance colours in organic white-light-emitting diodes, Isr. J. Chem. 52 (6) (2012) 529-539.

[152] A. Rizzo, O. Inganas, N. Solin, Preparation of phosphorescent amyloid-like protein fibrils, Chem. Eur. J. 16 (14) (2010) 4190-4195.

[153] U.S. Herrmann, A.K. Schütz, H. Shirani, D. Huang, D. Saban, M. Nuvolone, et al., Structure-based drug design identifies polythiophenes as antiprion compounds, Sci. Transl. Med. 7 (299) (2015) 299ra123.

[154] A. Herland, P. Björk, P.R. Hania, I.G. Scheblykin, O. Inganäs, Alignment of a conjugated polymer onto amyloid-like protein fibrils, Small 3 (2) (2007) 318-325.

[155] A. Herland, D. Thomsson, O. Mirzov, I.G. Scheblykin, O. Inganäs, Decoration of amyloid fibrils with luminescent conjugated polymers, J. Mater. Chem. 18 (1) (2008) 126-132.

[156] H. Tanaka, A. Herland, L.J. Lindgren, T. Tsutsui, M.R. Andersson, O. Inganas, Enhanced current efficiency from bio-organic light-emitting diodes using decorated amyloid fibrils with conjugated polymer, Nano Lett. 8 (9) (2008) 2858-2861.

[157] F.G. Bäcklund, J. Wigenius, F. Westerlund, O. Inganäs, N. Solin, Amyloid fibrils as dispersing agents for oligothiophenes: control of photophysical properties through nanoscale templating and flow induced fibril alignment, J. Mater. Chem. C 2 (37) (2014) 7811-7822. 
[158] C. Meier, I. Lifincev, M.E. Welland, Conducting core-shell nanowires by amyloid nanofiber templated polymerization, Biomacromolecules 16 (2) (2015) 558-563.

[159] J. Wang, X. Zhao, J. Li, X. Kuang, Y. Fan, G. Wei, et al., Electrostatic assembly of peptide nanofiber-biomimetic silver nanowires onto graphene for electrochemical sensors, ACS Macro Lett. 3 (6) (2014) 529-533.

[160] J.E. Yang, J.S. Park, E. Cho, S. Jung, S.R. Paik, Robust polydiacetylene-based colorimetric sensing material developed with amyloid fibrils of $\alpha$-synuclein, Langmuir 31 (5) (2015) 1802-1810.

[161] S.K. Maji, D. Schubert, C. Rivier, S. Lee, J.E. Rivier, R. Riek, Amyloid as a depot for the formulation of long-acting drugs, PLoS Biol. 6 (2) (2008) 240-252.

[162] S. Kasai, Y. Ohga, M. Mochizuki, N. Nishi, Y. Kadoya, M. Nomizu, Multifunctional peptide fibrils for biomedical materials, Biopolymers 76 (1) (2004) 27-33.

[163] N.P. Reynolds, M. Charnley, R. Mezzenga, P.G. Hartley, Engineered lysozyme amyloid fibril networks support cellular growth and spreading, Biomacromolecules 15 (2) (2014) 599-608.

[164] O. Barbosa, C. Ortiz, Á. Berenguer-Murcia, R. Torres, R.C. Rodrigues, R. FernandezLafuente, Strategies for the one-step immobilization-purification of enzymes as industrial biocatalysts, Biotechnol. Adv. 33 (5) (2015) 435-456.

[165] U. Baxa, V. Speransky, A.C. Steven, R.B. Wickner, Mechanism of inactivation on prion conversion of the Saccharomyces cerevisiae Ure2 protein, Proc. Natl. Acad. Sci. U. S. A. 99 (8) (2002) 5253-5260.

[166] U. Baxa, K.L. Taylor, J.S. Wall, M.N. Simon, N.Q. Cheng, R.B. Wickner, et al., Architecture of Ure2p prion filaments - the N-terminal domains form a central core fiber, J. Biol. Chem. 278 (44) (2003) 43717-43727.

[167] B. Schmuck, M. Sandgren, T. Härd, The kinetics of TEM1 antibiotic degrading enzymes that are displayed on Ure2 protein nanofibrils in a flow reactor, PLoS ONE 13 (4) (2018).

[168] H.-M. Chan, H.-W. Li, Multifunctional encoded self-assembling protein nanofibrils as platform for high-throughput and multiplexed detection of biomolecules, Anal. Chem. 83 (24) (2011) 9370-9377.

[169] L. Sasso, S. Suei, L. Domigan, J. Healy, V. Nock, M.A.K. Williams, et al., Versatile multi-functionalization of protein nanofibrils for biosensor applications, Nanoscale 6 (3) (2014) 1629-1634.

[170] M. Kaur, S. Roberts, J. Healy, L. Domigan, M. Vasudevamurthy, J.A. Gerrard, et al., Crystallin nanofibrils: a functionalizable nanoscaffold with broad applications manufactured from waste, ChemPlusChem 80 (5) (2015) 810-819.

[171] S.M. Pilkington, S.J. Roberts, S.J. Meade, J.A. Gerrard, Amyloid fibrils as a nanoscaffold for enzyme immobilization, Biotechnol. Prog. 26 (1) (2010) 93-100.

[172] C. Arnaud, From diseases to devices, Chem. Eng. News 86 (29) (2008) 48-51.

\section{Further reading}

[173] M.R. Chapman, L.S. Robinson, J.S. Pinkner, R. Roth, J. Heuser, M. Hammar, et al., Role of Escherichia coli curli operons in directing amyloid fiber formation, Science 295 (5556) (2002) 851-855. 